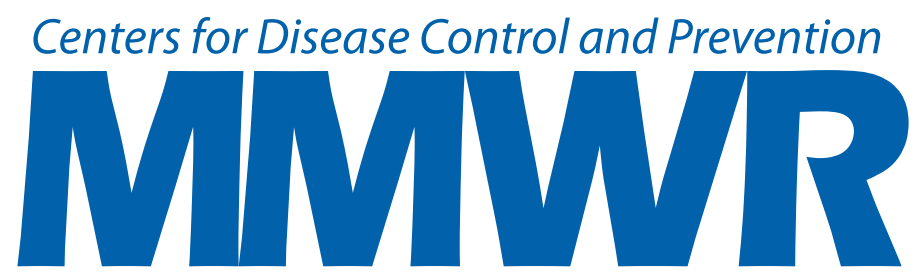

Morbidity and Mortality Weekly Report

Weekly / Vol. 64 / No. 38

October 2, 2015

\title{
Frequency of Tobacco Use Among Middle and High School Students - United States, 2014
}

\author{
Linda J. Neff, $\mathrm{PhD}^{1}$; René A. Arrazola, $\mathrm{MPH}^{1}$; Ralph S. Caraballo, $\mathrm{PhD}^{1}$; Catherine G. Corey, $\mathrm{MSPH}^{2}$; Shanna Cox, MSPH${ }^{1}$; Brian A. King, PhD ${ }^{1}$; \\ Conrad J. Choiniere, $\mathrm{PhD}^{2}$; Corinne G. Husten, $\mathrm{MD}^{2}$
}

The use of tobacco products during adolescence increases the risk for adverse health effects and lifelong nicotine addiction $(1,2)$. In 2014, an estimated 4.6 million middle and high school students were current users of any tobacco product, of whom an estimated 2.2 million were current users of two or more types of tobacco products (3). Symptoms of nicotine dependence are increased for multiple tobacco product users compared with single-product users (4,5). CDC and the Food and Drug Administration (FDA) analyzed data from the 2014 National Youth Tobacco Survey (NYTS) to determine how frequently (the number of days in the preceding 30 days) U.S. middle school (grades 6-8) and high school (grades 9-12) students used cigarettes, e-cigarettes, cigars, and smokeless tobacco products. Among current users ( $\geq 1$ day during the preceding 30 days) in high school, frequent use ( $\geq 20$ days during the preceding 30 days) was most prevalent among smokeless tobacco users $(42.0 \%)$, followed by cigarette smokers (31.6\%), e-cigarette users (15.5\%), and cigar smokers (13.1\%); a similar pattern was observed for those who used during all 30 days. Among current users in middle school, frequent use was greatest among smokeless tobacco users $(29.2 \%)$, followed by cigarette smokers $(20.0 \%)$, cigar smokers $(13.2 \%)$ and e-cigarette users $(11.8 \%)$. Current use of two or more types of tobacco products was common, even among students who used tobacco products $1-5$ days during the preceding 30 days: $77.3 \%$ for cigar smokers, $76.9 \%$ for cigarette smokers, $63.4 \%$ for smokeless tobacco users, and $54.8 \%$ for e-cigarettes users. Preventing youths from initiating the use of any tobacco product is important to tobacco use prevention and control strategies in the United States $(1,2)$. Monitoring the frequency and patterns of tobacco use among youths, including the use of two or more tobacco products, is important to inform evidence-based interventions to prevent and reduce all forms of tobacco use among youths (2).

NYTS is a cross-sectional, school-based, pencil-and-paper questionnaire administered to U.S. middle school and high school students. Information is collected to monitor the impact of comprehensive tobacco control policies and strategies and to inform FDA's regulatory actions (G). A three-stage cluster sampling procedure was used to generate a nationally representative sample of U.S. students in grades 6-12 who attend public and private schools. Of the 258 schools

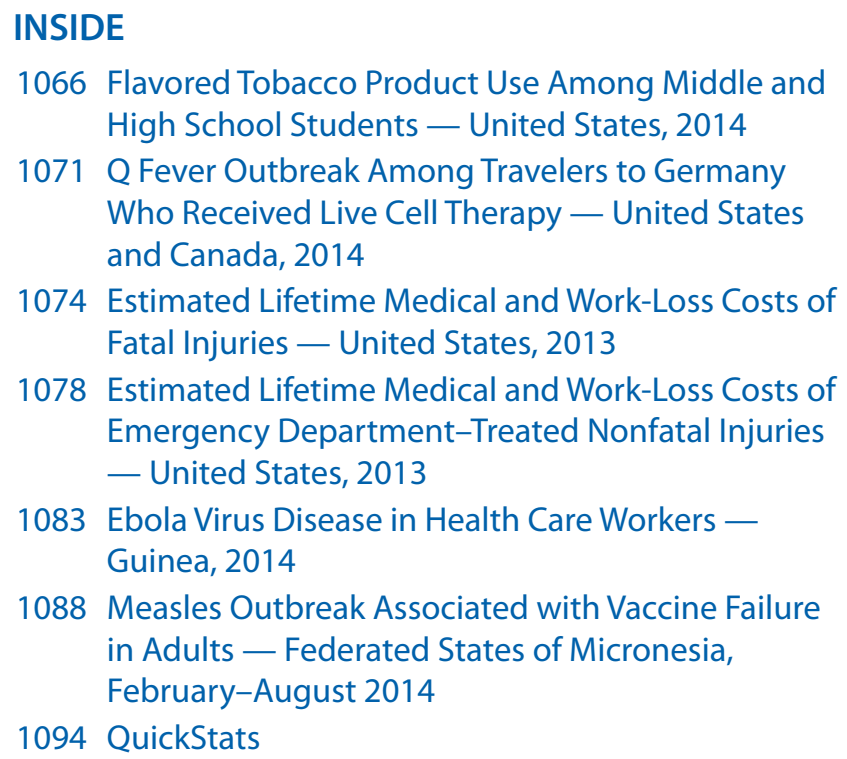

1074 Estimated Lifetime Medical and Work-Loss Costs of Fatal Injuries — United States, 2013

1078 Estimated Lifetime Medical and Work-Loss Costs of Emergency Department-Treated Nonfatal Injuries — United States, 2013

1083 Ebola Virus Disease in Health Care Workers Guinea, 2014

1088 Measles Outbreak Associated with Vaccine Failure in Adults - Federated States of Micronesia, February-August 2014

1094 QuickStats

Continuing Education examination available at http://www.cdc.gov/mmwr/cme/conted_info.html\#weekly.

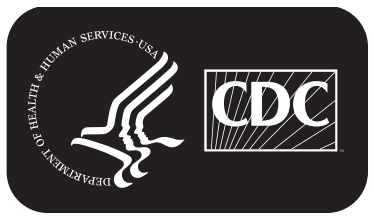

U.S. Department of Health and Human Services Centers for Disease Control and Prevention 
selected for the 2014 NYTS, 207 (80.2\%) participated, with a sample of 22,007 (91.4\%) among 24,084 eligible students; the overall response rate was $73.3 \%$. Current use (use $\geq 1$ day during the preceding 30 days) was assessed for nine products: cigarettes, cigars (defined as cigars, cigarillos, or little cigars), smokeless tobacco (defined as chewing tobacco, snuff, or dip), e-cigarettes, hookahs, tobacco pipes, snus, dissolvable tobacco (dissolvables), and bidis. Frequency of use (number of days during the preceding 30 days) was asked exclusively for four products: cigarettes, cigars, smokeless tobacco, and e-cigarettes; response options were 0 days, $1-2$ days, 3-5 days, 6-9 days, 10-19 days, 20-29 days, and all 30 days. Estimates of multiple tobacco product use were determined by assessing preceding 30-day use of only one other tobacco product or the use of two or more other tobacco products among current cigarette, e-cigarette, cigar, and smokeless tobacco users. Data were weighted to account for the complex survey design and to adjust for nonresponse. National prevalence estimates were computed with $95 \%$ confidence intervals and population estimates rounded down to the nearest 10,000.

In 2014, among middle and high school students who used at least one of these four products, an estimated 480,000 middle school and high school students smoked cigarettes, 390,000 used smokeless tobacco, 340,000 used e-cigarettes, and 170,000 smoked cigars on $\geq 20$ of the preceding 30 days (Table). Among high school students who were current users, $42.0 \%$ of smokeless tobacco users, $31.6 \%$ of cigarette smokers, $15.5 \%$ of e-cigarettes users, and $13.1 \%$ of cigar smokers reported using the product during $\geq 20$ of the preceding 30 days (Table); the proportion who used the product during 1-2 of the preceding 30 days was $52.0 \%$ for cigar smokers, $45.4 \%$ for e-cigarette users, $37.0 \%$ for cigarette smokers, and $26.6 \%$ for smokeless tobacco users. Among middle school students who were current users, $29.2 \%$ of smokeless tobacco users, $20.0 \%$ of cigarette smokers, $13.2 \%$ of cigar smokers, and $11.8 \%$ of e-cigarette users used the product on $\geq 20$ of the preceding 30 days; the proportion who used the product during 1-2 of the preceding 30 days was $54.5 \%$ for e-cigarette users, $44.3 \%$ for cigar smokers, $43.2 \%$ for cigarette smokers, and $38.4 \%$ for smokeless tobacco users.

Among middle school and high school students who reported using cigarettes, e-cigarettes, cigars, or smokeless tobacco on 1-5 days during the preceding 30 days, the percentages using multiple tobacco products were $77.3 \%$ for cigar smokers, $76.9 \%$ for cigarette smokers, $63.4 \%$ for smokeless tobacco users, and $54.8 \%$ for e-cigarette users (Figure).

\section{Discussion}

In 2014, among middle and high school students who used at least one of these four products, an estimated 480,000 middle school and high school students smoked cigarettes, 390,000 used smokeless tobacco, 340,000 used e-cigarettes, and 170,000 smoked cigars on $\geq 20$ of the preceding 30 days. The frequency of tobacco use among current users varied by school level and by type of tobacco product. High school students were more frequent users of tobacco products than

The MMWR series of publications is published by the Center for Surveillance, Epidemiology, and Laboratory Services, Centers for Disease Control and Prevention (CDC), U.S. Department of Health and Human Services, Atlanta, GA 30329-4027.

Suggested citation: [Author names; first three, then et al., if more than six.] [Report title]. MMWR Morb Mortal Wkly Rep 2015;64:[inclusive page numbers].

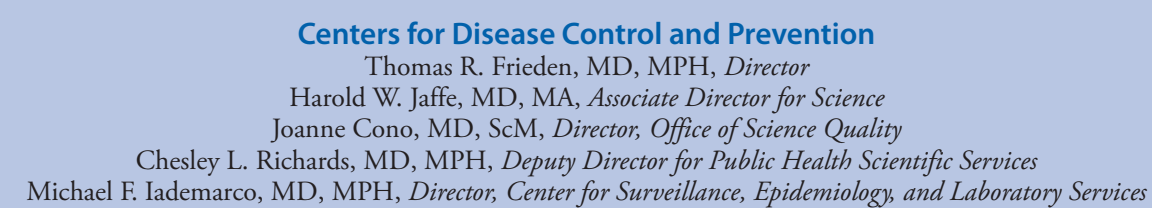

MMWR Editorial and Production Staff (Weekly)

Sonja A. Rasmussen, MD, MS, Editor-in-Chief

Charlotte K. Kent, PhD, MPH, Executive Editor Jacqueline Gindler, MD, Editor

Teresa F. Rutledge, Managing Editor

Douglas W. Weatherwax, Lead Technical Writer-Editor

Teresa M. Hood, MS, Jude C. Rutledge, Writer-Editors

MMWR Editorial Board

Timothy F. Jones, MD, Chairman

Matthew L. Boulton, MD, MPH Virginia A. Caine, MD

Katherine Lyon Daniel, MPH

Jonathan E. Fielding, MD, MPH, MBA

David W. Fleming, MD

\author{
William E. Halperin, MD, DrPH, MPH \\ King K. Holmes, MD, PhD \\ Robin Ikeda, MD, MPH \\ Rima F. Khabbaz, MD \\ Phyllis Meadows, PhD, MSN, RN \\ Jewel Mullen, MD, MPH, MPA
}

Martha F. Boyd, Lead Visual Information Specialist Maureen A. Leahy, Julia C. Martinroe, Stephen R. Spriggs, Brian E. Wood, Moua Yang Visual Information Specialists

Quang M. Doan, MBA, Phyllis H. King, Teresa C. Moreland, Terraye M. Starr Information Technology Specialists 
TABLE. Frequency of current use of cigarettes, e-cigarettes, cigars, and smokeless tobacco among middle and high school students, ${ }^{*}$ by number of days of use during the preceding 30 days - National Youth Tobacco Survey, United States, 2014

\begin{tabular}{|c|c|c|c|c|c|c|c|c|c|c|c|c|}
\hline \multirow[b]{3}{*}{ Days of use } & \multicolumn{12}{|c|}{ Tobacco product } \\
\hline & \multicolumn{3}{|c|}{ Cigarettes } & \multicolumn{3}{|c|}{ E-cigarettes } & \multicolumn{3}{|c|}{ Cigars } & \multicolumn{3}{|c|}{ Smokeless tobacco } \\
\hline & $\%$ & $(95 \% \mathrm{Cl})$ & $\begin{array}{l}\text { Estimated no. } \\
\text { of users }^{\dagger}\end{array}$ & $\%$ & $(95 \% \mathrm{Cl})$ & $\begin{array}{c}\text { Estimated no. } \\
\text { of users }^{\dagger}\end{array}$ & $\%$ & $(95 \% \mathrm{Cl})$ & $\begin{array}{l}\text { Estimated no. } \\
\text { of users }^{\dagger}\end{array}$ & $\%$ & $(95 \% \mathrm{Cl})$ & $\begin{array}{l}\text { Estimated no. } \\
\text { of users }^{\dagger}\end{array}$ \\
\hline \multicolumn{13}{|l|}{ High school } \\
\hline $1-2$ days & 37.0 & $(34.0-40.0)$ & 500,000 & 45.4 & $(41.9-49.0)$ & 910,000 & 52.0 & $(46.9-57.0)$ & 620,000 & 26.6 & $(23.0-30.6)$ & 220,000 \\
\hline $3-5$ days & 12.3 & $(10.1-14.9)$ & 160,000 & 16.2 & $(14.0-18.5)$ & 320,000 & 18.7 & $(16.0-21.8)$ & 220,000 & 11.1 & $(8.3-14.6)$ & 90,000 \\
\hline 6-9 days & 9.7 & $(7.5-12.5)$ & 130,000 & 12.0 & $(10.0-14.3)$ & 240,000 & 7.5 & $(5.7-9.8)$ & 90,000 & 8.2 & $(5.7-11.6)$ & 60,000 \\
\hline $10-19$ days & 9.4 & (7.4-11.9) & 120,000 & 10.9 & $(9.1-13.0)$ & 220,000 & 8.8 & $(6.6-11.6)$ & 100,000 & 12.2 & $(8.9-16.6)$ & 100,000 \\
\hline 20-29 days & 9.0 & $(7.1-11.4)$ & 120,000 & 5.8 & $(4.5-7.5)$ & 110,000 & 4.6 & $(3.3-6.3)$ & 50,000 & 11.2 & $(8.4-14.7)$ & 90,000 \\
\hline All 30 days & 22.6 & $(19.2-26.5)$ & 310,000 & 9.7 & $(7.5-12.5)$ & 190,000 & 8.5 & $(6.6-10.8)$ & 100,000 & 30.8 & $(26.5-35.4)$ & 250,000 \\
\hline \multicolumn{13}{|c|}{ Middle school } \\
\hline $1-2$ days & 43.2 & $(32.4-54.7)$ & 120,000 & 54.5 & $(49.5-59.3)$ & 240,000 & 44.3 & $(36.2-52.7)$ & 90,000 & 38.4 & $(23.6-55.6)$ & 70,000 \\
\hline $3-5$ days & 17.9 & $(12.1-25.8)$ & 50,000 & 17.3 & $(13.7-21.6)$ & 70,000 & 14.3 & $(9.6-20.8)$ & 30,000 & 13.2 & $(8.0-21.1)$ & 20,000 \\
\hline 6-9 days & 10.1 & $(6.3-15.7)$ & 20,000 & 9.2 & $(7.0-12.0)$ & 40,000 & 15.0 & $(9.2-23.4)$ & 30,000 & 13.0 & $(7.8-20.9)$ & 20,000 \\
\hline $10-19$ days & 8.7 & $(5.7-13.2)$ & 20,000 & 7.3 & $(5.2-10.1)$ & 30,000 & 13.2 & $(7.4-22.5)$ & 20,000 & $6.2^{\S}$ & $(2.8-12.8)$ & 10,000 \\
\hline 20-29 days & $5.8^{\S}$ & $(2.9-11.2)$ & 10,000 & $3.9^{\S}$ & $(2.1-7.3)$ & 10,000 & $3.3^{\S}$ & $(1.5-6.9)$ & $<10,000$ & $11.3^{\S}$ & $(4.1-27.6)$ & 20,000 \\
\hline All 30 days & 14.2 & $(9.0-21.8)$ & 40,000 & 7.9 & $(5.4-11.4)$ & 30,000 & 9.9 & $(6.2-15.6)$ & 20,000 & 17.9 & $(11.1-27.7)$ & 30,000 \\
\hline
\end{tabular}

Abbreviation: $\mathrm{Cl}=$ confidence interval.

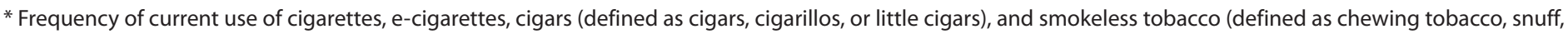
or dip) was determined by asking participants on how many days they used each of these tobacco products during the preceding 30 days.

${ }^{\dagger}$ Estimated number of users was rounded down to the nearest 10,000.

$\S$ Data are statistically unreliable because the sample size was $<50$ or the relative standard error was $>30 \%$.

middle school students, which is consistent with trajectories of initiation and escalation of use during adolescence; for example, the average age of first use of cigarettes is 15 years, and the average age of beginning daily cigarette use is 18 years (1). Studies have shown that early age of onset of cigarette smoking increases the risk for heavier use, long-term use, and greater difficulty quitting $(4,7)$. The impacts of early initiation also might hold true for users of other tobacco products, given that exposure to nicotine is the main cause of tobacco product dependence (1). Studies have documented that even among U.S. adolescent tobacco users who only used a single tobacco product on 1-2 days during the previous month, many reported symptoms of tobacco dependence, including strong cravings (14\%), irritability and restlessness when not using tobacco $(11 \%)$, strong desire to use the product $(6 \%)$, and wanting to use the tobacco product within 30 minutes of awakening (1\%) (5).

This report highlights the importance of understanding not only frequency of tobacco product use, but also patterns of using multiple products. A high level of multiple tobacco product use was observed, even among students using e-cigarettes, cigarettes, cigars or smokeless tobacco on 1-5 of the preceding 30 days. The prevalence of reporting symptoms of dependence is $2-3$ times higher for multiple product users than for single-product users $(4,5)$. The use of multiple tobacco products among adolescents increases exposure (inhalation or oral absorption) to nicotine and other harmful by-products contained in these tobacco products (2).

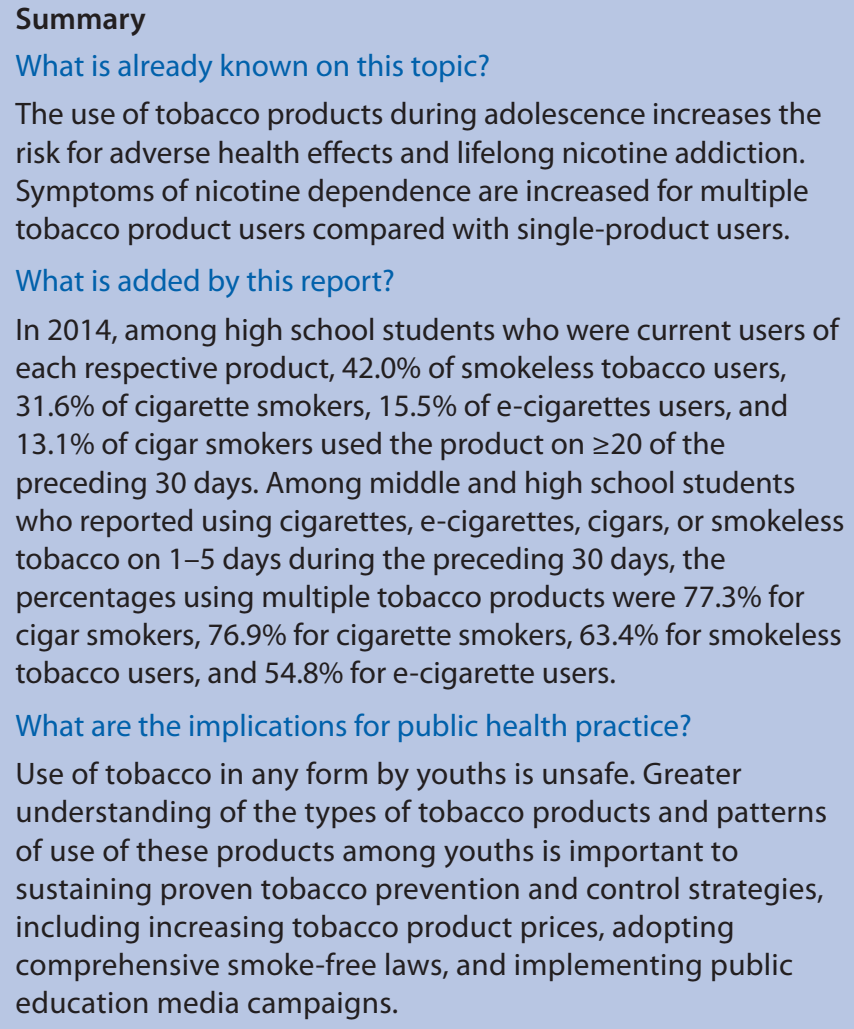

The findings in this report are subject to at least four limitations. First, all the data were self-reported and might be subject to recall bias or social desirability bias. Second, the data were 
FIGURE. Percentage of middle and high school students who reported using more than one type of tobacco product, ${ }^{*}$ by number of days used during the preceding 30 days, among current cigarette smokers, e-cigarette users, cigar smokers, and smokeless tobacco users ${ }^{\dagger} \_$National Youth Tobacco Survey, United States, 2014

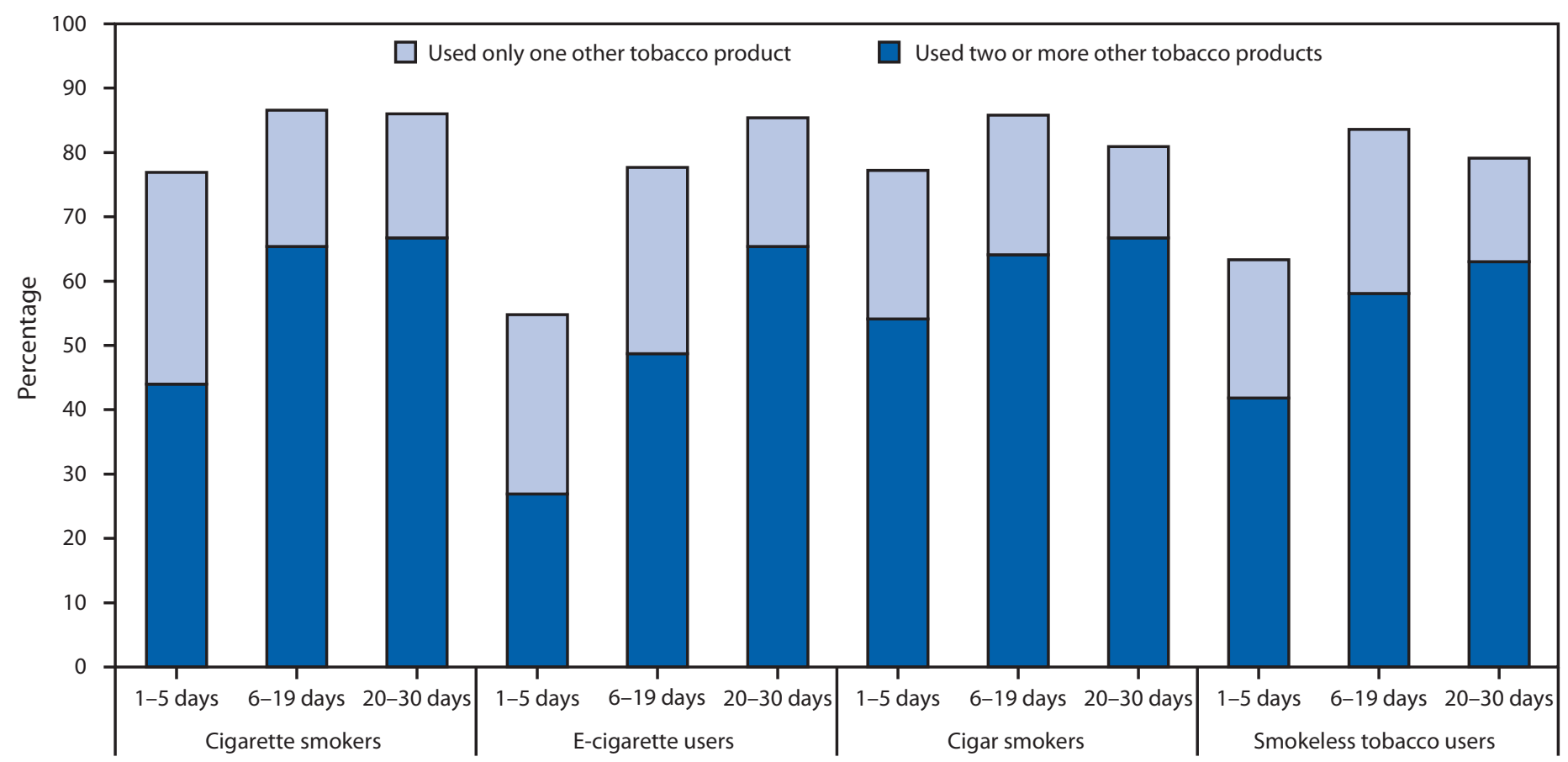

Current tobacco product users

\begin{abstract}
* Current use was assessed for nine types of tobacco products: cigarettes; cigars (defined as cigars, cigarillos, or little cigars); smokeless tobacco (defined as chewing tobacco, snuff, or dip); e-cigarettes; hookahs; tobacco pipes; snus; dissolvable tobacco (dissolvables); and bidis. Current use for each product type was defined as use on $\geq 1$ days during the preceding 30 days.

† Use of one or two or more of the other eight types of tobacco products was assessed among current cigarette smokers, e-cigarette users, cigar smokers, and smokeless tobacco users.
\end{abstract}

collected from students who attended either public or private schools, and might not be generalizable to all U.S. middle and high school-aged youths. Third, frequency of use was estimated by the number of days the respondent reported using the tobacco product during the preceding 30 days; however, the pattern of use, primary product used, or which products were used on specific days, could not be obtained from these data. Therefore, the extent to which products were used together on the same days could not be determined. Finally, frequency of use of hookahs, tobacco pipes, snus, dissolvables, and bidis was not collected; therefore, the frequency of use of these tobacco products could not be assessed.

Preventing youths from beginning use of any tobacco product is important to tobacco use prevention and control strategies in the United States (2). Most adult cigarette smokers start smoking before age 18 years, and nearly all transition from occasional to daily smoking occurs before age 26 years $(1,2)$. Use of tobacco in any form by youths is unsafe $(1)$. Therefore, the increased use of emerging tobacco products, such as e-cigarettes and hookahs, and the use of multiple types of tobacco products, is a public health concern. Greater understanding of the types of tobacco products and patterns of use of these products among youths is important for ensuring that proven tobacco prevention and control strategies, including increasing tobacco product prices, adopting comprehensive smoke-free laws, and implementing public education media campaigns, address the diverse types of tobacco products used by youth $(8-10)$.

${ }^{1}$ Office on Smoking and Health, National Center for Chronic Disease Prevention and Health Promotion, CDC; ${ }^{2}$ Center for Tobacco Products, Food and Drug Administration.

Corresponding author: Linda J. Neff, len2@cdc.gov, 770-488-8467.

\section{References}

1. US Department of Health and Human Services. The health consequences of smoking - 50 years of progress. Atlanta, GA: US Department of Health and Human Services, CDC; 2014. Available at http://www.cdc. gov/tobacco/data_statistics/sgr/50th-anniversary/index.htm.

2. US Department of Health and Human Services. Preventing tobacco use among youth and young adults: a report of the Surgeon General. Atlanta, GA: US Department of Health and Human Services, CDC; 2012. Available at http://www.cdc.gov/tobacco/data_statistics/sgr/2012/index.htm. 
3. Arrazola RA, Singh T, Corey CG, et al. Tobacco use among middle and high school students-United States, 2011-2014. MMWR Morb Mortal Wkly Rep 2015;64:381-5.

4. Lanza ST, Vasilenko SA. New methods shed light on age of onset as a risk factor for nicotine dependence. Addict Behav 2015;50:161-4.

5. Apelberg BJ, Corey CG, Hoffman AC, et al. Symptoms of tobacco dependence among middle and high school tobacco users: results from the 2012 National Youth Tobacco Survey. Am J Prev Med 2014;47(Suppl 1):S4-14.

6. CDC. 2014 National Youth Tobacco Survey: methodology report. Atlanta, GA: US Department of Health and Human Services, CDC; 2015.

7. Kendler KS, Myers J, Damaj MI, Chen X. Early smoking onset and risk for subsequent nicotine dependence: a monozygotic co-twin control study. Am J Psychiatry 2013;170:408-13.
8. CDC. Key outcome indicators for evaluating comprehensive tobacco control programs. Atlanta, GA: US Department of Health and Human Services, CDC; 2005. Available at http://www.cdc.gov/tobacco/ tobacco_control_programs/surveillance_evaluation/key_outcome.

9. Family Smoking Prevention and Tobacco Control Act [Pub. L. No. 111-31, H.R. 1256 (2009)]. Available at http://www.gpo.gov/fdsys/ pkg/PLAW-111 publ31/html/PLAW-111 publ31.htm.

10. CDC. Best practices for comprehensive tobacco control programs-2014. Atlanta, GA: US Department of Health and Human Services, CDC; 2014. Available at http://www.cdc.gov/tobacco/stateandcommunity/ best_practices/pdfs/2014/comprehensive.pdf. 


\title{
Flavored Tobacco Product Use Among Middle and High School Students - United States, 2014
}

\author{
Catherine G. Corey, $\mathrm{MSPH}^{1}$; Bridget K. Ambrose, $\mathrm{PhD}^{1}$; Benjamin J. Apelberg, $\mathrm{PhD}^{1}$; Brian A. King ${ }^{2}$
}

The 2009 Family Smoking Prevention and Tobacco Control Act prohibits "characterizing flavors" (e.g., candy, fruit, and chocolate) other than tobacco and menthol in cigarettes; however, characterizing flavors are not currently prohibited in other tobacco products (1). Analyses of retail sales data suggest that U.S. consumption of flavored noncigarette tobacco products, including flavored cigars and flavored e-cigarettes, has increased in recent years $(2,3)$. There is growing concern that widely marketed varieties of new and existing flavored tobacco products might appeal to youths (2) and could be contributing to recent increases in the use of tobacco products, including e-cigarettes and hookah, among youths (4). CDC and the Food and Drug Administration (FDA) analyzed data from the 2014 National Youth Tobacco Survey (NYTS) to determine the prevalence of past 30 day use (current use) of flavored e-cigarette, hookah tobacco, cigar, pipe tobacco or smokeless tobacco products, and menthol cigarettes among middle and high school students, and the proportion of current tobacco product users who have used flavored products. An estimated $70.0 \%$ (3.26 million) of all current youth tobacco users had used at least one flavored tobacco product in the past 30 days. Among current users, $63.3 \%$, (1.58 million) had used a flavored e-cigarette, 60.6\%, (1.02 million) had used flavored hookah tobacco, and 63.5\% $(910,000)$ had used a flavored cigar in the past 30 days. Given the millions of current youth tobacco users, it is important for comprehensive tobacco prevention and control strategies to address all forms of tobacco use, including flavored tobacco products, among U.S. youths.

The NYTS is a cross-sectional, school-based, selfadministered, pencil-and-paper questionnaire administered to U.S. middle school (grades 6-8) and high school (grade 9-12) students. Information is collected to monitor the impact of comprehensive tobacco control policies and strategies and to inform FDA regulatory actions $(1,5)$. For the 2014 NYTS, a three-stage cluster sampling procedure was used to generate a nationally representative sample of U.S. students attending public and private schools in grades 6-12. Among 258 schools selected for the 2014 NYTS, 207 (80.2\%) participated, with a sample of 22,007 (91.4\%) among 24,084 eligible students; the overall response rate was $73.3 \%$.

Participants were asked about past 30-day use of eight different tobacco products: cigarettes; e-cigarettes; hookah; cigars (defined as cigars, cigarillos or little cigars); tobacco in pipes; smokeless tobacco (defined as chewing tobacco, snuff or dip); snus*; and dissolvable tobacco products (dissolvables). ${ }^{\dagger}$ Current use for each product was defined as using a product on $\geq 1$ day during the preceding 30 days. "Any tobacco" was defined as using any of the tobacco products on $\geq 1$ day during the past 30 days. "Any smokeless tobacco" was defined as using smokeless tobacco, snus, or dissolvables on $\geq 1$ day during the past 30 days.

Participants also were asked about any current use of tobacco products that were "flavored to taste like menthol (mint), alcohol (wine, cognac), candy, fruit, chocolate, or other sweets." Participants could select from a list of options to designate the flavored tobacco product or products they had used, which included each of the seven noncigarette tobacco product types and "I did not use flavored tobacco in the past 30 days." Among those who reported any use of each respective product in the past 30 days, those who selected the flavored product were categorized as flavored product users, those who did not select the flavored product were categorized as only nonflavored product users, and those who did not provide any response to the flavored use question were categorized as missing flavor status. Because studies have suggested adolescent underreporting of menthol status of brands that exclusively or predominately produce menthol cigarettes (e.g., Newport and Kool) $(6,7)$, menthol cigarette smoking was ascertained from responses to two questions: "During the past 30 days, were the cigarettes that you usually smoked menthol?" and "During the past 30 days, what brand of cigarettes did you usually smoke?" Among current cigarette smokers, those reporting "Yes" to the menthol question, or who reported "Newport" or "Kool" as the usual cigarette brand, were categorized as menthol smokers. Subsequently, respondents who reported "No" to the menthol question, or who did not report "Newport" or "Kool" brands, were categorized as nonmenthol smokers. All other current cigarette smokers were categorized as missing menthol smoking status.

Data were weighted to account for the complex survey design and adjusted for nonresponse. National prevalence estimates were calculated with $95 \%$ confidence intervals and weighted population estimates were rounded down

\footnotetext{
* Snus is a smokeless, spitless tobacco product.

$\dagger$ Participants also were asked about past 30-day use of bidis. Because information on use of flavored bidis was not available, bidi use was excluded from the analysis.
} 
to the nearest 10,000 . Two-sided chi-squared tests were used to assess statistically significant differences between demographic subgroups at $\mathrm{p}<0.05$.

Among middle and high school students in 2014, an estimated 1.58 million used a flavored e-cigarette, 1.02 million used flavored hookah tobacco, 910,000 used flavored cigars, 900,000 used menthol cigarettes, 690,000 used flavored smokeless tobacco products, and 120,000 used flavored pipe tobacco in the past 30 days (Table). Among current users of any tobacco product, $70.0 \%$ reported using at least one flavored tobacco product in the past 30 days, corresponding to an estimated 3.26 million middle and high school students. The proportion of current tobacco users who reported flavored product use in the past 30 days was $63.5 \%$ for cigars, $63.3 \%$ for e-cigarettes, $60.6 \%$ for hookah, $58.8 \%$ for any smokeless tobacco, $53.6 \%$ for menthol cigarettes and $42.3 \%$ for tobacco in pipes.
Among all current tobacco users, a higher proportion of high school than middle school students reported use of flavored e-cigarettes, flavored hookah, flavored smokeless tobacco, and any flavored product, while the proportion of male and female users who reported flavored product use was generally similar. Among current cigarette smokers, a greater proportion of non-Hispanic blacks reported menthol cigarette use (70.5\%) than non-Hispanic whites (51.4\%) and Hispanics (52.3\%); however, among current users of other tobacco products, nonHispanic blacks generally had lower prevalence of flavored product use than non-Hispanic whites.

Among high school students only, 24.5\% reported using one or more tobacco products in the past 30 days (i.e., current use). Current use of at least one flavored product was reported by $17.9 \%$ of all high school students, whereas $5.8 \%$ reported using only nonflavored tobacco products (Figure).

TABLE. Percentage of middle and high school students currently using tobacco products* who reported using flavored products ${ }^{\dagger}$ during the preceding 30 days, by sex and race/ethnicity — National Youth Tobacco Survey, United States, 2014

Tobacco product

\begin{tabular}{|c|c|c|c|c|c|c|c|c|c|c|c|c|c|c|}
\hline \multirow[b]{3}{*}{ Overall } & \\
\hline & \multicolumn{2}{|c|}{ Any tobacco ${ }^{\S}$} & \multicolumn{2}{|c|}{ E-cigarettes } & \multicolumn{2}{|c|}{ Hookah } & \multicolumn{2}{|c|}{ Cigars } & \multicolumn{2}{|c|}{ Cigarettes? } & \multicolumn{2}{|c|}{$\begin{array}{c}\text { Any smokeless } \\
\text { tobacco*** }^{* *}\end{array}$} & \multicolumn{2}{|c|}{ Pipe tobacco } \\
\hline & $\%$ & $(95 \% \mathrm{Cl})$ & $\%$ & $(95 \% \mathrm{Cl})$ & $\%$ & $(95 \% \mathrm{Cl})$ & $\%$ & $(95 \% \mathrm{Cl})$ & $\%$ & $(95 \% \mathrm{Cl})$ & $\%$ & $(95 \% \mathrm{Cl})$ & $\%$ & $(95 \% \mathrm{Cl})$ \\
\hline $\begin{array}{l}\text { Estimated no. of } \\
\text { flavored users }\end{array}$ & \multicolumn{2}{|c|}{$3,260,000$} & \multicolumn{2}{|c|}{$1,580,000$} & \multicolumn{2}{|c|}{$1,020,000$} & \multicolumn{2}{|c|}{910,000} & \multicolumn{2}{|c|}{900,000} & \multicolumn{2}{|c|}{690,000} & \multicolumn{2}{|c|}{120,000} \\
\hline $\begin{array}{l}\text { Prevalence of flavored } \\
\text { use among all } \\
\text { students }\end{array}$ & 12.0 & $(10.9-13.2)$ & 5.9 & $(4.9-7.1)$ & 3.9 & $(3.3-4.6)$ & 3.5 & $(3.0-4.0)$ & 3.4 & $(2.9-4.0)$ & 2.6 & $(2.2-3.1)$ & 0.5 & $(0.4-0.6)$ \\
\hline $\begin{array}{l}\text { Proportion of flavored } \\
\text { use among current } \\
\text { product users }\end{array}$ & 70.0 & $(67.4-72.4)$ & 63.3 & $(59.8-66.7)$ & 60.6 & $(56.5-64.5)$ & 63.5 & $(59.4-67.3)$ & 53.6 & $(47.9-59.1)$ & 58.8 & $(53.8-63.7)$ & 42.3 & $(34.2-50.9)$ \\
\hline \multicolumn{15}{|l|}{ School type } \\
\hline Middle school & 57.0 & $(49.7-64.0)$ & 55.1 & $(50.3-59.8)$ & 44.3 & $(35.5-53.5)$ & 56.6 & $(43.7-68.7)$ & 48.4 & $(38.1-58.8)$ & 36.1 & $(24.9-49.1)$ & 33.3 & $(20.7-48.8)$ \\
\hline High school & 73.0 & $(70.6-75.3)$ & 65.1 & $(60.9-69.1)$ & 63.8 & $(59.6-67.7)$ & 64.7 & $(60.6-68.6)$ & 54.5 & $(48.4-60.4)$ & 64.7 & $(60.2-68.9)$ & 44.0 & $(34.9-53.5)$ \\
\hline \multicolumn{15}{|l|}{ Sex } \\
\hline Female & 70.4 & $(66.8-73.8)$ & 66.5 & $(61.7-71.0)$ & 64.5 & $(58.7-69.9)$ & 58.9 & $(52.1-65.3)$ & 55.8 & $(48.7-62.7)$ & 40.7 & $(29.9-52.5)$ & 42.3 & $(28.5-57.6)$ \\
\hline Male & 69.5 & $(66.6-72.3)$ & 60.6 & $(56.0-65.0)$ & 55.9 & $(50.8-61.0)$ & 65.8 & $(61.2-70.1)$ & 51.8 & $(45.4-58.1)$ & 63.3 & $(58.4-68.0)$ & 40.7 & $(31.2-51.1)$ \\
\hline \multicolumn{15}{|l|}{ Race/Ethnicity } \\
\hline White, non-Hispanic & 75.0 & $(72.2-77.5)$ & 68.2 & $(63.8-72.3)$ & 67.2 & $(61.9-72.0)$ & 70.1 & $(64.4-75.3)$ & 51.4 & $(43.8-59.0)$ & 67.5 & $(61.1-73.2)$ & 39.1 & $(27.5-52.1)$ \\
\hline Black, non-Hispanic & 54.7 & $(49.0-60.3)$ & 44.0 & $(35.4-53.0)$ & 42.4 & $(32.9-52.6)$ & 54.8 & $(47.1-62.4)$ & 70.5 & $(60.1-79.1)$ & —§§ & - & - & - \\
\hline Hispanic & 66.1 & $(61.2-70.6)$ & 57.9 & $(53.3-62.3)$ & 56.4 & $(49.0-63.6)$ & 55.9 & $(49.7-61.9)$ & 52.3 & $(44.3-60.1)$ & 32.5 & $(25.3-40.6)$ & 42.7 & $(31.6-54.6)$ \\
\hline $\begin{array}{l}\text { Other race, } \\
\text { non-Hispanic }\end{array}$ & 72.8 & $(67.4-77.6)$ & 61.3 & $(54.2-68.1)$ & 65.9 & $(55.8-74.7)$ & 67.2 & $(56.1-76.7)$ & 58.1 & $(48.9-66.8)$ & 60.0 & $(45.6-72.9)$ & - & - \\
\hline
\end{tabular}

Abbreviation: $\mathrm{Cl}=$ confidence interval.

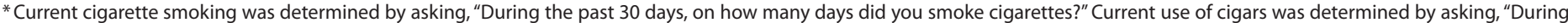

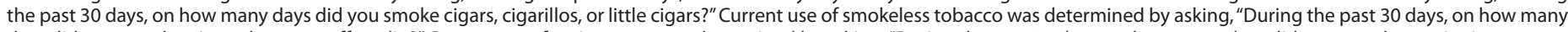

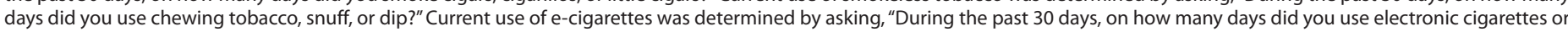

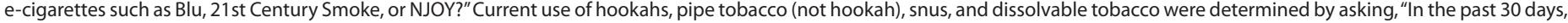
which of the following products have you used on at least one day?"

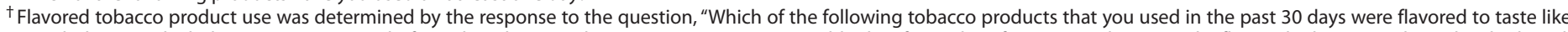

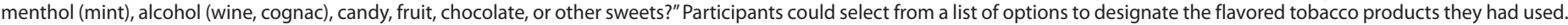

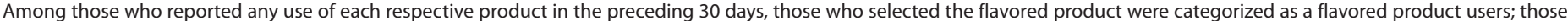

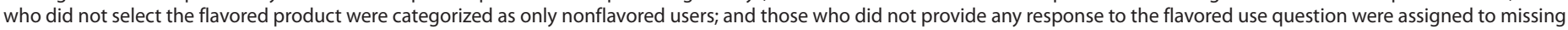
flavor status.

$\S$ Any tobacco is use of cigarettes, cigars, smokeless tobacco, e-cigarettes, hookahs, tobacco pipes, snus, or dissolvables on $\geq 1$ day in the preceding 30 days.

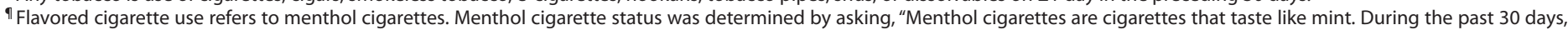

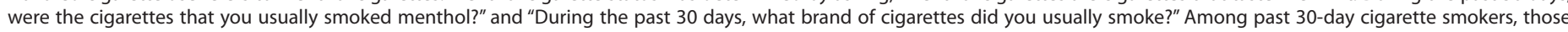

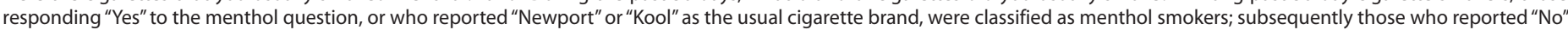

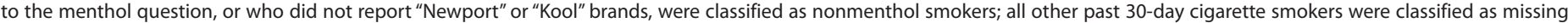
menthol smoking status.

** Any smokeless tobacco is current use of smokeless tobacco (chewing tobacco, snuff, or dip), snus, or dissolvables on $\geq 1$ day in the preceding 30 days.

${ }^{+\dagger}$ The estimated numbers of flavored tobacco product users were rounded down to the nearest 10,000.

$\S \S$ Data are statistically unreliable because the sample size was $<50$ or the relative standard error was $>30 \%$. 
FIGURE. Percentage of high school students who used flavored tobacco products or only nonflavored tobacco products* during the preceding 30 days - National Youth Tobacco Survey, United States, 2014

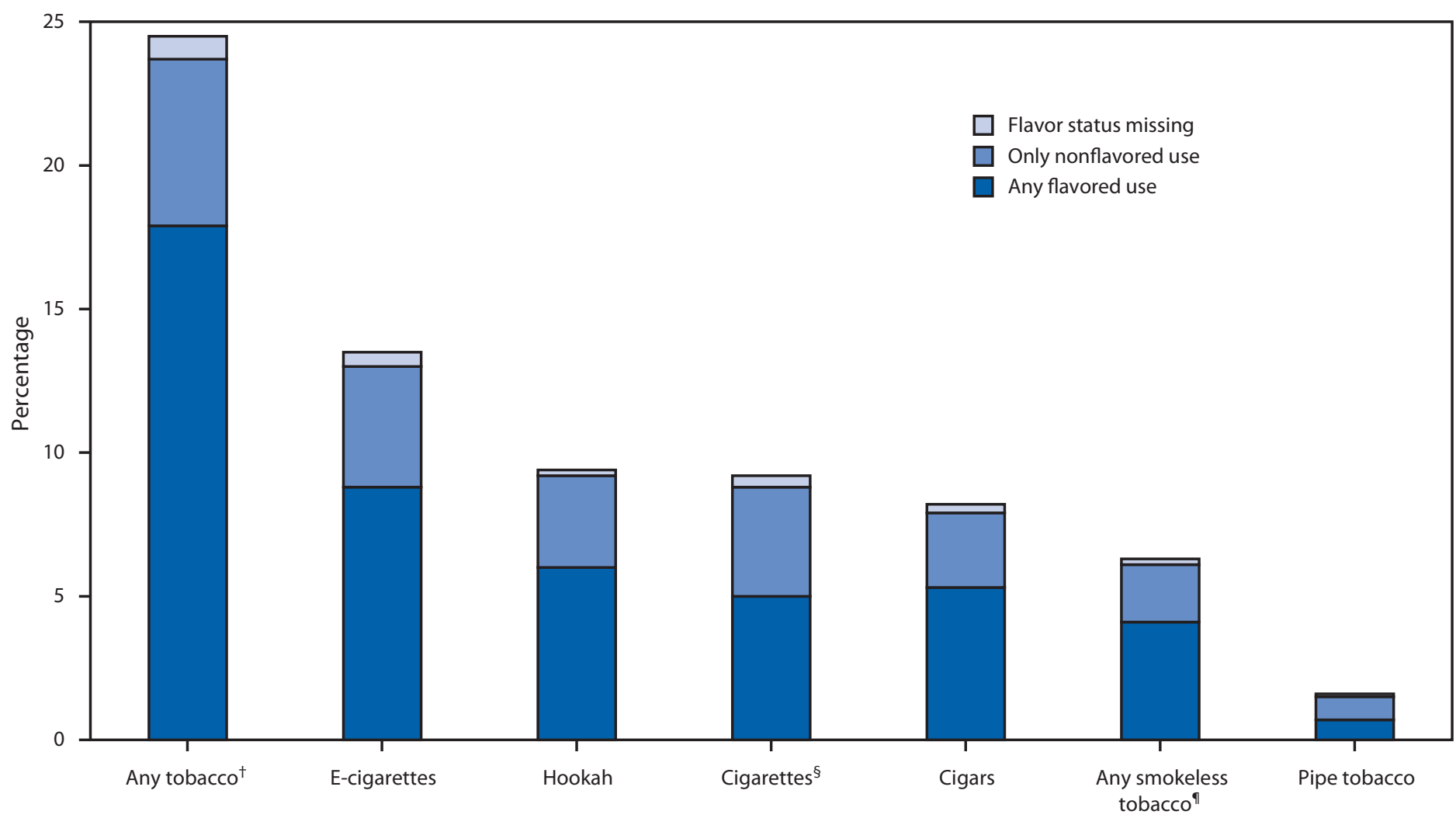

Tobacco product used

\begin{abstract}
* Flavored tobacco product use was determined by the response to the question, "Which of the following tobacco products that you used in the preceding 30 days were flavored to taste like menthol (mint), alcohol (wine, cognac), candy, fruit, chocolate, or other sweets?" Participants could select from a list of options to designate the flavored tobacco products they had used. Among those who reported any use of each respective product in the preceding 30 days, those who selected the flavored product were assigned as a flavored product users, those who did not select the flavored product were assigned as only nonflavored users, and those who did not provide any response to the flavored use question were assigned to missing flavor status.

${ }^{\dagger}$ Any tobacco is use of cigarettes, cigars, smokeless tobacco, e-cigarettes, hookahs, tobacco pipes, snus, or dissolvables on $\geq 1$ day in the preceding 30 days.

$\S$ Flavored cigarette use refers to menthol cigarettes. Menthol cigarette status was determined by asking," Menthol cigarettes are cigarettes that taste like mint. During the past 30 days, were the cigarettes that you usually smoked menthol?" and "During the past 30 days, what brand of cigarettes did you usually smoke?" Among cigarette smokers during the preceding 30 days, those who responded "Yes" to the menthol question, or who reported "Newport" or "Kool" as the usual cigarette brand, were classified as menthol smokers; subsequently those who responded "No" to the menthol question, or who did not report "Newport" or "Kool" brands, were classified as nonmenthol smokers; all other cigarette smokers during the preceding 30 days were classified as missing flavor status for flavored cigarettes.

ף Any smokeless tobacco is use of smokeless tobacco (chewing tobacco, snuff, or dip), snus, or dissolvables on $\geq 1$ day during the preceding 30 days.
\end{abstract}

E-cigarettes (8.8\%) were the most commonly used flavored tobacco product among high school students, followed by hookah $(6.0 \%)$, cigars $(5.3 \%)$, menthol cigarettes $(5.0 \%)$, any smokeless tobacco $(4.1 \%)$, and tobacco in pipes $(0.7 \%)$.

\section{Discussion}

Among U.S. middle and high school students who used a tobacco product in the preceding 30 days in 2014, an estimated 3.26 million used a flavored tobacco product. In 2014, among middle and high school students who used a tobacco product within the past 30 days, $70.0 \%$ reported using at least one flavored tobacco product, including 1.58 million e-cigarette users, 1.02 million hookah users, 910,000 cigar smokers, and 900,000 menthol cigarette smokers. Consequently, millions of youths are exposed, through inhalation or oral absorption, to nicotine and harmful constituents from these tobacco products (8). Nicotine exposure during adolescence, a critical window for brain development, causes addiction, is more likely to lead to sustained tobacco use, and might have lasting adverse consequences for brain development (8).

The proportion of current users who reported flavored use was consistently high across tobacco products including among cigar smokers $(63.5 \%)$, e-cigarette users $(63.3 \%)$, and hookah users $(60.6 \%)$. The popularity of flavors across the range of 
tobacco products suggests that flavoring might have broad appeal to young tobacco users. Therefore, it is important that comprehensive tobacco prevention and control strategies for youths address all forms of flavored tobacco products and not just cigarettes.

The findings in this report are subject to at least five limitations. First, data were collected only from students who attended either public or private schools and might not be generalizable to all middle and high school-aged youths. Second, flavored tobacco product use was ascertained from a check-all-that-apply response, which might yield lower estimates than forced-choice response options. Third, NYTS is a paper-pencil based survey; therefore, students might report current use of a flavored product, but also report that they did not use any form of that product in past 30 days. In this analysis, a student had to first report any use of a tobacco product in the past 30 days before flavored tobacco use status was determined. Fourth, inconsistencies in responses to menthol and usual brand questions required the development of a measure of menthol cigarette status that relied on responses to both questions. Finally, the flavor question referred to use of any flavored products, whereas the menthol and cigarette brand questions referred to the usual cigarettes smoked. Additionally, the flavor measure reflects any flavored use in the preceding 30 days, and not how frequently flavored products were used.

Sustained efforts to implement proven tobacco control policies and strategies are needed to prevent all forms of tobacco use, including flavored tobacco products, among U.S. youths. For example, several local jurisdictions, including New York City (New York), ${ }^{\circledR}$ Chicago (Illinois), 9 Providence (Rhode Island), ${ }^{* *}$ and Santa Clara (California) have acted to limit or restrict sales of flavored tobacco products in their communities. ${ }^{\dagger \dagger}$ Additional strategies that can reduce youth tobacco use include increasing the price of tobacco products, adopting comprehensive smoke-free laws, implementing advertising and promotion restrictions and national public education media campaigns, and raising the minimum age of purchase for all tobacco products to age 21 years $(9,10)$.

\footnotetext{
$\$$ Available at http://www.nyc.gov/html/doh/downloads/pdf/smoke/flavoredlaw.pdf.

I Available at http://www.cityofchicago.org/content/dam/city/depts/bacp/ tobacco/flavoredtobaccord04212014.pdf.

** Available at http://www.providenceri.com/efile/2036.

$\dagger \dagger$ Available at https://www.sccgov.org/sites/sccphd/en-us/Partners/ TobaccoPrevention/Documents/SCC\%20Tobacco\%20Retail\%20Permit\%20 Ordinance_6.24.2014_FINAL.pdf.
}

\section{Summary}

What is already known on this topic?

Retail sales data suggest that U.S. consumption of flavored tobacco products, including flavored cigars and flavored e-cigarettes, has increased in recent years. There is growing concern that widely marketed varieties of new and existing flavored tobacco products might appeal to youths and could be contributing to recent increases in the use of tobacco products, including e-cigarettes and hookah, among youths.

What is added by this report?

In 2014, among middle and high school students, 1.58 million e-cigarette users, 1.02 million hookah users, 910,000 cigar smokers used flavored varieties of these products during the preceding 30 days. Among current tobacco users, $70.0 \%$ reported using at least one flavored tobacco product in the past 30 days, including $63.5 \%$ of cigar smokers, $63.3 \%$ of e-cigarette users, and $60.6 \%$ of hookah users.

What are the implications for public health practice?

In 2014, millions of youths were exposed, through inhalation or oral absorption, to nicotine and harmful constituents from tobacco products. Sustained efforts to implement proven tobacco control policies and strategies (e.g., increasing the price of tobacco products, adopting comprehensive smoke-free laws, implementing advertising and promotion restrictions and national public education media campaigns, and raising the minimum age of purchase for all tobacco products to age 21 years) are needed to prevent all forms of tobacco use, including flavored tobacco products, among U.S. youths.

\section{Acknowledgments}

René A. Arrazola, Office on Smoking and Health, National Center for Chronic Disease Prevention and Health Promotion, CDC; Brian L. Rostron, Center for Tobacco Products, Food and Drug Administration.

\footnotetext{
${ }^{1}$ Center for Tobacco Products, Food and Drug Administration; ${ }^{2}$ Office on Smoking and Health, National Center for Chronic Disease Prevention and Health Promotion, CDC.

Corresponding author: Catherine G. Corey, catherine.corey@fda.hhs.gov, 301-796-7396.
}

\section{References}

1. Family Smoking Prevention and Tobacco Control Act [Pub. L. No. 111-31, H.R. 1256 (2009)]. Available at http://www.gpo.gov/fdsys/ pkg/PLAW-111 publ31/html/PLAW-111publ31.htm.

2. Delnevo CD, Giovenco DP, Ambrose BK, Corey CG, Conway KP. Preference for flavoured cigar brands among youth, young adults and adults in the USA. Tob Control 2015;24:389-94.

3. Giovenco D, Hammond D, Corey CG, Ambrose BK, Delnevo CD. E-cigarette market trends in traditional U.S. retail channels, 2012-2013. Nicotine Tob Res 2015;10:1279-83. 
4. Arrazola RA, Singh T, Corey CG, et al. Tobacco use among middle and high school students-United States, 2011-2014. MMWR Morb Mortal Wkly Rep 2015;64:381-5.

5. CDC. Key outcome indicators for evaluating comprehensive tobacco control programs. Atlanta, GA: US Department of Health and Human Services, CDC; 2005. Available at http://www.cdc.gov/tobacco/ tobacco_control_programs/surveillance_evaluation/key_outcome.

6. Giovino GA, Villanti AC, Mowery PD, et al. Differential trends in cigarette smoking in the USA: is menthol slowing progress? Tob Control 2015;24:28-37.

7. Hersey JC, Nonnemaker JM, Homsi G. Menthol cigarettes contribute to the appeal and addiction potential of smoking for youth. Nicotine Tob Res 2010;12(Suppl 2):S136-46.
8. US Department of Health and Human Services. The health consequences of smoking - 50 years of progress. Atlanta, GA: US Department of Health and Human Services, CDC; 2014. Available at http://www.cdc. gov/tobacco/data_statistics/sgr/50th-anniversary/index.htm.

9. CDC. Best practices for comprehensive tobacco control programs - 2014. Atlanta, GA: US Department of Health and Human Services, CDC; 2014. Available at http://www.cdc.gov/tobacco/stateandcommunity/ best_practices/pdfs/2014/comprehensive.pdf.

10. Institute of Medicine. Public health implications of raising the minimum age of legal access to tobacco products. Washington, DC: National Academies of Sciences; 2015. Available at http://iom.nationalacademies. org/Reports/2015/TobaccoMinimumAgeReport.aspx. 


\title{
Q Fever Outbreak Among Travelers to Germany Who Received Live Cell Therapy — United States and Canada, 2014
}

\begin{abstract}
Misha P. Robyn, DVM ${ }^{1,2}$; Alexandra P. Newman, DVM²; Michael Amato, MPH 3 ; Mary Walawander 3 ; Cynthia Kothe ${ }^{4}$; James D. Nerone ${ }^{4}$; Cynthia Pomerantz ${ }^{4}$; Casey Barton Behravesh, DVM ${ }^{5}$; Holly M. Biggs, MD ${ }^{1,5}$; F. Scott Dahlgren, MSPH 5 ; Emily G. Pieracci, DVM ${ }^{1,5}$; Yvonne Whitfield, MPH ${ }^{6}$; Doug Sider, $\mathrm{MD}^{6}$; Omar Ozaldin, $\mathrm{MSc}^{7}$; Lisa Berger, $\mathrm{MD}^{7}$; Peter A. Buck, DVM ${ }^{8}$; Mark Downing, MD ${ }^{9,10}$; Debra Blog, $\mathrm{MD}^{2}$
\end{abstract}

During September-November 2014, the New York State Department of Health (NYSDOH) was notified of five New York state residents who had tested seropositive for Coxiella burnetii, the causative agent of Q fever. All five patients had symptoms compatible with Q fever (e.g., fever, fatigue, chills, and headache) and a history of travel to Germany to receive a medical treatment called "live cell therapy" (sometimes called "fresh cell therapy") in May 2014. Live cell therapy is the practice of injecting processed cells from organs or fetuses of nonhuman animals (e.g., sheep) into human recipients (1). It is advertised to treat a variety of health conditions. This practice is unavailable in the United States; however, persons can travel to foreign locations to receive injections. Local health departments interviewed the patients, and NYSDOH notified CDC and posted a report on CDC's Epidemic Information Exchange to solicit additional cases. Clinical and exposure information for each patient was reported to the Robert Koch Institute in Germany, which forwarded the information to local health authorities. A Canada resident who also received live cell therapy in May 2014 was diagnosed with Q fever in July 2014. Clinicians should be aware of health risks, such as Q fever and other zoonotic diseases, among patients with a history of receiving treatment with live cell therapy products.

The five New York patients had traveled in a group of 10-15 persons to the state of Rhineland-Palatinate in Germany to receive intramuscular injections of fetal sheep cells from a German physician on May 30, 2014. A Canada resident, who received intramuscular injections of fetal sheep cells from the same German physician on May 28, 2014, sought medical care in June 2014 for fever, pain, and erythema at the site of the injection. She received a diagnosis of Q fever in July 2014, and public health authorities were notified. Under International Health Regulations, the Public Health Agency of Canada notified German authorities in September 2014. At the time of notification, the ministry of health of the federal state of Rhineland-Palatinate was investigating an outbreak of human $Q$ fever associated with inhalation exposure to a sheep flock that was used for production of fetal sheep cell injections by the German physician.

In September, the German physician notified patients treated during January-July 2014 of their potential Q fever exposure. This prompted Q fever testing of the five patients in New York, three of whom had already sought medical care for symptoms. The other two patients had experienced symptoms but had not sought medical care until notification of their potential $\mathrm{Q}$ fever exposure. The test results, with positive $\mathrm{Q}$ fever titers, were reported to NYSDOH and prompted investigation by local health departments. No additional U.S. or Canada residents with positive Q fever titers and history of intramuscular injections of fetal sheep cells in Germany have been identified. The identities and nationalities of the other persons in the travel group are unknown to U.S. and Canadian public health authorities. It is not known whether the other persons did not get tested for Q fever, tested negative, or did not report an exposure to fetal sheep cell injections

An outbreak-associated case of Q fever was defined as an illness consisting of clinical signs and symptoms compatible with Q fever, and a single IgG titer $\geq 1: 128$ to $C$. burnetii phase II antigen by immunofluorescence assay in a person who received live cell therapy in Germany during May 2014 (2). Among the six identified cases, the median patient age was 62 years (range $=59-83$ years). Four of the six patients were female. None of the patients reported other potential exposures to $Q$ fever, with the exception of one patient who reported contact with sheep horn or bone. Three patients reported preexisting medical conditions: one patient with atrial fibrillation and kidney stones, one patient with Parkinson disease and osteoarthritis, and one patient with multiple sclerosis.

Signs and symptoms of $\mathrm{Q}$ fever began within approximately 1 week of receipt of the intramuscular injections of fetal sheep cells. The majority of symptoms were reported as lasting approximately 10-90 days; however, 9-10 months after exposure, three patients continued to report symptoms of fatigue, chills, sweats, and difficulty sleeping (Table). One patient had initially reported no symptoms during an interview with the local health department after his positive titers were reported in November 2014; however, in February 2015, he informed his physician that symptoms had been occurring since the injections in May.

The patients were tested for Q fever phase I and phase II antibodies at 2-6 months after exposure, using indirect immunofluorescence assay. C. burnetii undergoes antigenic phase variation, between a virulent phase I form and an avirulent phase II form. During acute infection, phase II antibodies 
TABLE. Signs and symptoms reported by six Q fever patients who underwent live cell therapy — United States and Canada, 2014

\begin{tabular}{|c|c|c|c|c|c|c|}
\hline Sign/Symptom & Patient 1 & Patient $2^{*}$ & Patient 3 & Patient 4 & Patient 5 & Patient 6 \\
\hline Fever & $x$ & & $x$ & $\mathrm{x}$ & $\mathrm{x}$ & $\mathrm{x}$ \\
\hline Sweats & $x$ & & $x$ & $x$ & $x$ & \\
\hline Fatigue & $x$ & $x$ & & $x$ & $\mathrm{x}$ & $\mathrm{x}$ \\
\hline Headache & $x$ & & $\mathrm{x}$ & & $x$ & \\
\hline Chills & $x$ & $x$ & $x$ & & & \\
\hline Malaise & & & $x$ & $x$ & $x$ & \\
\hline Cellulitis & & & $x$ & & $x$ & $\mathrm{x}$ \\
\hline Confusion & $x$ & & & & & \\
\hline Retrobulbar pain & $x$ & & & & & \\
\hline Injection site abscess & & & $\mathrm{x}$ & & & \\
\hline Cough & & & $x$ & & & \\
\hline Dizziness & & & $x$ & & & \\
\hline Shortness of breath & & & $x$ & & & $x$ \\
\hline Sore throat & & & $x$ & & & \\
\hline Dry mouth & & & $x$ & & & \\
\hline Diarrhea & & & $x$ & & & \\
\hline Difficulty sleeping & & & & $\mathrm{x}$ & & \\
\hline Joint pain & & & & & $\mathrm{x}$ & \\
\hline Myalgia & & & & & $x$ & \\
\hline Duration & $10-30$ days & $\begin{array}{l}9 \text { months (fatigue } \\
\text { and chills were } \\
\text { ongoing as of } \\
\text { February 2015) }\end{array}$ & $2-3$ months & $\begin{array}{l}\text { 14-30 days (fatigue } \\
\text { and difficulty } \\
\text { sleeping were } \\
\text { ongoing as of } \\
\text { February 2015) }\end{array}$ & $\begin{array}{l}30 \text { days (fatigue } \\
\text { and sweats were } \\
\text { ongoing as of } \\
\text { February 2015) }\end{array}$ & $\begin{array}{l}10 \text { days (fatigue } \\
\text { continued for } \\
\text { several months) }\end{array}$ \\
\hline
\end{tabular}

* Patient 2 initially reported no symptoms.

appear first and are higher than phase I antibodies. All patients' phase I IgG titers were elevated (1:512-1:2,048), but were lower than phase II IgG titers (1:4,096-1:65,536), suggesting acute disease. Phase I IgM titers were elevated in four patients $(1: 128-1: 8,192)$ and phase II IgM titers were elevated in all patients (1:64-1:32,768). All patients were treated with doxycycline after receiving a diagnosis of $\mathrm{Q}$ fever.

All six patients were initially interviewed by their local health departments; only two of the five New York patients agreed to a follow-up interview by NYSDOH. The two patients reported that a group had traveled to Germany for injections twice each year for the past 5 years. They chose to receive injections of fetal sheep cells to improve their general health and vitality, and had not previously experienced signs or symptoms of illness after injections. They reported that they were not informed of a risk for $\mathrm{Q}$ fever infection before injection.

\section{Discussion}

The treatment known as live cell therapy was developed in Switzerland during the 1930s by Paul Niehans. Practitioners have used organs, glands, and fetuses of multiple species, including sheep, cows, and sharks* (1).

No published clinical evidence supporting therapeutic claims of the treatment known as live cell therapy is available. It is advertised as having anti-aging effects and as a treatment for multiple conditions and diseases (e.g., erectile dysfunction,

\footnotetext{
*Additional information available at http://www.extendlife.com/livecell.php.
}

depression, and joint, neurologic, heart, kidney, lung, endocrine, and liver disease). ${ }^{\dagger}$ Serious adverse events have been reported, including anaphylaxis, vasculitis, encephalitis, polyradiculitis, clostridial infections, paresis, and death (3-5).

The treatment known as live cell therapy is a type of xenotransplantation when it involves administration of live cells from a nonhuman animal source into a human recipient (G). Xenotransplantation carries a public health risk for transmission of known and unknown infectious agents from the donor organism to the human recipient and possible recombination or reassortment to form new pathogens (G). There is a theoretic potential for dissemination of disease from the original recipient to others. For this reason, discussions on safety requirements for xenotransplantation by international and domestic public health agencies continue to occur ( 7 ).

Regulation of xenotransplantation varies among countries. In the United States, the Food and Drug Administration (FDA) regulates xenotransplantation products as Biologic Drugs under section 351 of the Public Health Service Act ${ }^{\circledR}$ and the Federal Food, Drug, and Cosmetic Act. FDA approval of a Biologics License Application (BLA) is required to introduce, or deliver for introduction, a biologic product into interstate commerce. FDA has not approved a BLA for a xenotransplantation product known as live cell therapy. If a xenotransplantation product

\footnotetext{
$\dagger$ Additional information available at http://www.janson-mueller.de/index php?id $=22 \& \mathrm{~L}=2$.

$\$ 42$ U.S.C. 262.

21 U.S.C. 321 et seq.
} 
is proposed for use in a clinical investigation in the United States, an Investigational New Drug Application would be required. In Canada, xenotransplantation cell therapy products are regulated as drugs under the Food and Drugs Act** and the Food and Drug Regulations. ${ }^{\dagger \dagger}$ Authorities in Canada have not authorized for sale any xenotransplantation products, nor have any clinical trials that involve xenotransplantation been authorized. In Germany, xenotransplantation products are regulated under the Medicinal Products Act; however, an attempt to ban fresh cell therapy in 1997 was later determined to be null and void because the federal law does not cover drugs manufactured by doctors only for use in their own patients (8). According to an assessment supported by the World Health Organization and its partners, during January 1994-September 2009, xenotransplantation procedures were identified in 12 different countries, of which nine had no clear national regulations on xenotransplantation (9).

This outbreak highlights one of the public health issues associated with xenotourism, the travel outside a country of residence for the purpose of participating in xenotransplantation programs. FDA recommends that xenotransplantation product recipients enrolled in research studies remain under lifelong surveillance with periodic clinical and laboratory monitoring and that both they and their intimate contacts refrain from blood and tissue donation (G). However, other than self-reporting, no method to identify returned xenotourists is available. Clinicians should be aware of xenotourism and consider the potential for zoonotic disease in a patient with a history of xenotransplantation.

\footnotetext{
** R.S.C., 1985, c. F-27.

$\dagger \dagger$ C.R.C., c. 870
}

\section{Acknowledgments}

Stephen Moore, Ryan Walton, Bryna Warshawsky, MD, Public Health Ontario. Samir N. Patel, PhD, Public Health Ontario and University of Toronto; Maja George, PhD, Robert Koch Institute and European Centre for Disease Prevention and Control; Ann Sullivan-Frohm, Christina Hidalgo, MPH, Philip Kurpiel, PhD, New York State Department of Health; Canada IHR National Focal Point Office, Public Health Agency of Canada.

\footnotetext{
${ }^{1}$ Epidemic Intelligence Service, CDC; ${ }^{2} \mathrm{New}$ York State Department of Health; ${ }^{3}$ Erie County Department of Health; ${ }^{4}$ Ulster County Department of Health and Mental Health; ${ }^{5}$ Division of Vector-Borne Diseases, National Center for Emerging and Zoonotic Infectious Diseases, CDC; ${ }^{6}$ Public Health Ontario; ${ }^{7}$ Toronto Public Health; ${ }^{8}$ Centre for Food-borne, Environmental and Zoonotic Infectious Diseases, Public Health Agency of Canada; ${ }^{9}$ Saint Joseph's Health Centre, Toronto, Ontario; ${ }^{10}$ Department of Medicine, University of Toronto.

Corresponding author: Misha P. Robyn, mrobyn@cdc.gov, 518-486-5245.
}

\section{Summary}

What is already known on this topic?

Q fever is a zoonotic disease caused by Coxiella burnetii and is usually transmitted through inhalation of air contaminated with animal excreta. The disease is considered to be underdiagnosed because symptoms are nonspecific and can vary from patient to patient, making diagnosis difficult.

What is added by this report?

During September-October 2014, the New York State Department of Health identified Q fever in five patients with exposure to a treatment known as live cell therapy, an alternative medicine practice involving injections of fetal sheep cells, which is a type of xenotransplantation. Investigation revealed that a group of U.S. residents traveled to Germany twice a year to receive this treatment.

What are the implications for public health practice?

Clinicians should consider zoonotic diseases, such as Q fever, in patients whose history includes receipt of a treatment known as live cell therapy. International travel for xenotransplantation procedures can facilitate transmission of zoonotic disease.

\section{References}

1. US Congress, Office of Technology Assessment. Unconventional cancer treatments, OTA-H-405. Washington, DC: US Government Printing Office; 1990.

2. Centers for Disease Control and Prevention (CDC). Notes from the field: $\mathrm{Q}$ fever outbreak associated with goat farms - Washington and Montana, 2011. MMWR Morb Mortal Wkly Rep 2011;60:1393.

3. Bohl J, Goebel HH, Pötsch L, et al. Complications following cell therapy. Z Rechtsmed 1989;103:1-20.

4. Goebel HH, Walther G, Meuth M. Fresh cell therapy followed by fatal coma. J Neurol 1986;233:242-7.

5. The Lancet. Cell therapy suspended. Lancet 1987;330:503.

6. Center for Biologics and Research. Guidance for industry: source animal, product, preclinical, and clinical issues concerning the use of xenotransplantation products in humans. US Department of Health and Human Services, Food and Drug Administration, Center for Biologics and Research; 2003. Available at http://www.fda.gov/ BiologicsBloodVaccines/GuidanceComplianceRegulatoryInformation/ Guidances/Xenotransplantation/ucm074354.htm.

7. World Health Organization. Second WHO Global Consultation on Regulatory Requirements for Xenotransplantation Clinical Trials. Geneva, Switzerland; October 17-19, 2011. Available at http://www.who.int/ transplantation/xeno/report2nd_global_consultation_xtx.pdf?ua=1.

8. Federal Constitutional Court. Ban on fresh cell production is void. Bund has no regulatory powers. Press release No. 18/2000; February 16, 2000 [German]. Available at http://www.bundesverfassungsgericht.de/ SharedDocs/Pressemitteilungen/DE/2000/bvg00-018.html.

9. Sgroi A, Bühler LH, Morel P, Sykes M, Noel L. International human xenotransplantation inventory. Transplantation 2010;90:597-603. 


\title{
Estimated Lifetime Medical and Work-Loss Costs of Fatal Injuries - United States, 2013
}

\author{
Curtis Florence, $\mathrm{PhD}^{1}$; Thomas Simon, $\mathrm{PhD}^{2}$; Tamara Haegerich, $\mathrm{PhD}^{3}$; Feijun Luo, $\mathrm{PhD},{ }^{1}$; Chao Zhou, $\mathrm{PhD}^{1}$
}

Injury-associated deaths have substantial economic consequences. In 2013, unintentional injury was the fourth leading cause of death, suicide was the tenth, and homicide was the sixteenth; these three causes accounted for approximately 187,000 deaths in the United States (1). To assess the economic impact of fatal injuries, CDC analyzed death data from the National Vital Statistics System (1) for 2013, along with cost of injury data using the Web-Based Injury Statistics Query and Reporting System (1). This report updates a previous study that analyzed death data from the year 2000 (2), and employs recently revised methodology for determining the costs of injury outcomes, which uses the most current economic data and incorporates improvements for estimating medical costs associated with injury (3). Number of deaths, crude and agespecific death rates, and total lifetime work-loss costs and medical costs were calculated for fatal injuries by sex, age group, intent (intentional versus unintentional), and mechanism of injury. During 2013, the rate of fatal injury was 61.0 per 100,000 population, with combined medical and work-loss costs exceeding $\$ 214$ billion. Costs from fatal injuries represent approximately one third of the total $\$ 671$ billion medical and work-loss costs associated with all injuries in 2013 (3). The magnitude of the economic burden associated with injuryassociated deaths underscores the need for effective prevention.

The number of injury-associated deaths in the United States during 2013 was obtained from National Vital Statistics System, and lifetime costs were obtained from the Web-based Injury Statistics Query and Reporting System database (1). Injury death rates were calculated using the U.S. Census Bureau's bridged race population estimates for 2013. Lifetime cost estimates, which include lifetime work-loss and medical costs, were computed from average costs of earnings and treating injuries in 2010, adjusted to 2013 prices. For each death record, lifetime work-loss cost was assigned according to the sex and age of the decedent. The sex-and age-specific probability of surviving to a given age was multiplied by the mean earnings of persons of that sex and age using U.S. Census Bureau earnings data, assuming that no one would live beyond age 102 years. Lifetime medical costs were assigned by injury diagnosis and mechanism, place of death, and decedent's age (3). Medical costs were derived from various sources that measure the cost of transport, examination by a coroner or medical examiner, and health care in multiple settings, including emergency departments, hospitals, and nursing homes. Work-loss costs were developed using earnings data from the U.S. Census Bureau's Current Population Survey and life expectancy data from CDC's National Center for Health Statistics. Number of deaths, rates and total lifetime medical and work-loss costs were examined for 2013, stratified by sex, age, and intent of injury. The distribution of costs by mechanism and intent of injury was also examined for the five highest-cost mechanisms, stratified by intent.

The total estimated lifetime medical and work-loss costs associated with fatal injuries in 2013 was $\$ 214$ billion (Table). Males accounted for approximately $78 \%$ of these costs and for $67 \%$ of injury deaths. Approximately two thirds of injury deaths were unintentional, and these deaths also represented a majority of the cost ( $\$ 129.7$ billion [61\%]). Approximately one fifth of injury-related deaths were suicides, and the cost of these deaths ( $\$ 50.8$ billion) accounted for about $24 \%$ of all injury death costs. Approximately $8 \%$ of injury-related deaths were homicides, and the associated costs $(\$ 26.4$ billion) accounted for about $12 \%$ of the medical and work-loss costs for all injury deaths. Male victims represented $82 \%$ of the costs for suicide ( $\$ 41.7$ billion) and $86 \%$ of the costs for homicide ( $\$ 22.5$ billion).

Overall, rates of fatal injury increased with age; however, this pattern differed by injury intent, with higher homicide rates among young persons and higher suicide rates among middleaged adults. The costs associated with fatal injury were concentrated among adolescents and young adults aged 15-24 years and adults aged 25-64 years. The lowest costs and the lowest proportion of costs were associated with injury deaths in persons aged $\geq 65$ years. These differences are also reflected in the mean cost of injury death by intent (Figure 1). The mean medical and work-loss cost of any injury death in 2013 was slightly more than $\$ 1.1$ million, ranging from just below $\$ 1$ million for unintentional injuries, to in excess of $\$ 1.6$ million for homicides; the cost per suicide was $\$ 1.2$ million.

Among all injury deaths, drug poisonings accounted for $26 \%$ of the costs associated with fatal injuries, followed by transportation-related deaths $(23 \%)$, firearm-related deaths $(22 \%)$, deaths from suffocation (9\%), and deaths resulting from falls (5\%) (Figure 2). Considerable differences were observed in the proportional distribution of costs accounted for by each mechanism among unintentional deaths, homicides, 
TABLE. Injury deaths, rates per 100,000 population, and estimated lifetime medical and work-loss costs, by sex, age group, and intent — United States, 2013

\begin{tabular}{|c|c|c|c|c|c|c|c|c|}
\hline \multirow[b]{2}{*}{ Intent } & \multirow[b]{2}{*}{ Total } & \multicolumn{2}{|c|}{ Sex } & \multicolumn{5}{|c|}{ Age group (yrs) } \\
\hline & & Male & Female & $0-14$ & $15-24$ & $25-44$ & $45-64$ & $\geq 65$ \\
\hline \multicolumn{9}{|l|}{ All intents* } \\
\hline No. of deaths & 192,945 & 129,912 & 63,033 & 5,501 & 21,320 & 53,205 & 58,350 & 54,524 \\
\hline Rate $^{\dagger}$ & 61.03 & 83.46 & 39.28 & 9.00 & 48.50 & 63.87 & 70.23 & 121.97 \\
\hline Costs ${ }^{\S}$ & 214,394 & 166,717 & 47,355 & 7,786 & 41,527 & 95,540 & 55,250 & 9,164 \\
\hline \multicolumn{9}{|l|}{ Unintentional } \\
\hline No. of deaths & 130,557 & 81,916 & 48,641 & 3,993 & 11,619 & 31,563 & 37,414 & 45,942 \\
\hline Rate $^{\dagger}$ & 41.30 & 52.63 & 30.31 & 6.54 & 26.43 & 37.89 & 45.03 & 102.77 \\
\hline Costs $\S$ & 129,726 & 97,091 & 32,585 & 5,628 & 22,371 & 56,079 & 35,112 & 7,439 \\
\hline \multicolumn{9}{|l|}{ Homicide } \\
\hline No. of deaths & 16,121 & 12,726 & 3,395 & 896 & 4,329 & 6,817 & 3,164 & 905 \\
\hline Rate $^{\dagger}$ & 5.10 & 8.18 & 2.12 & 1.47 & 9.85 & 8.18 & 3.81 & 2.02 \\
\hline Costs ${ }^{\S}$ & 26,350 & 22,572 & 3,817 & 1,235 & 8,622 & 12,858 & 3,159 & 202 \\
\hline \multicolumn{9}{|l|}{ Suicide } \\
\hline No. of deaths & 41,149 & 32,055 & 9,094 & 395 & 4,878 & 12,899 & 15,756 & 7,215 \\
\hline Rate $^{\dagger}$ & 13.02 & 20.59 & 5.67 & 0.65 & 11.10 & 15.49 & 18.96 & 16.14 \\
\hline Costs ${ }^{\S}$ & 50,795 & 41,747 & 8,913 & 664 & 9,578 & 23,242 & 15,038 & 1,443 \\
\hline
\end{tabular}

Sources: CDC's National Center for Health Statistics National Vital Statistics System for numbers of deaths. Pacific Institute for Research and Evaluation for unit cost estimates. U.S. Census Bureau for population estimates. Numbers and rates computed using the Web-Based Injury Statistics Query and Reporting System (WISQARS) (http://www.cdc.gov/injury/wisqars).

* All intents include legal intervention and undetermined intent of injury.

$\dagger$ Deaths per 100,000 population.

$\S$ In millions of 2013 U.S. dollars. Cost estimates were computed from average lifetime work-loss and medical costs by mechanism and intent of injury. The base year for average costs was 2010. Base year costs were indexed to 2013 prices and applied to 2013 death counts. Lifetime medical costs refer to the medical costs associated with the fatal injury event.

FIGURE 1. Mean medical and work-loss costs per injury death, by intent* — United States, 2013

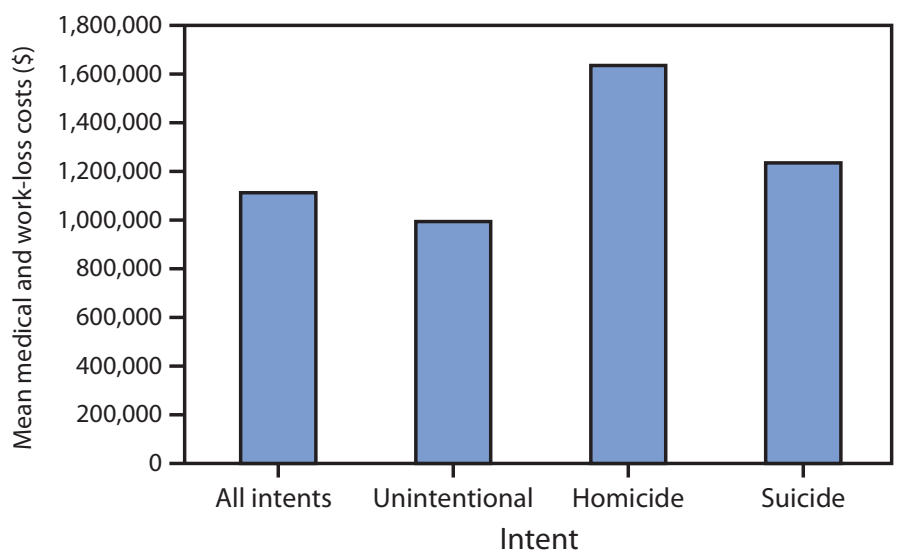

* All intents category includes legal intervention and undetermined intent of injury, in addition to unintentional, homicide, and suicide.

and suicides. Firearm-related fatal injuries accounted for $75 \%$ of the homicide-associated costs and $48 \%$ of the suicideassociated costs. Other leading mechanisms contributing to suicide costs were suffocation (including hanging) (29\%) and drug poisoning $(12 \%)$. Costs associated with unintentional injury deaths were primarily related to transportation-related deaths (37\%) and drug poisonings (38\%).

\section{Discussion}

Fatal injuries have a profound effect on victim's families and society in general. These deaths also have substantial medical and work-loss costs. Implementing effective prevention strategies can help to reduce these costs. The most recent study examining the medical and work-loss costs related to all types of injury analyzed data from the year 2000 (2). Since publication of that report, substantial changes have occurred in the causes and mechanisms of fatal injuries. For example, the rate of drug poisoning deaths doubled during 1999-2013 (4), and the suicide rate increased by 16\% during 2000-2010 (5), whereas the death rate from motor vehicle crashes declined during 2000-2013 (6). These changes in the cause and mechanism of injury deaths suggest that previous estimates of cost associated with fatal injuries are not representative of current costs. This report uses the most recently available data on fatal injuries, as well as an updated costing methodology that incorporates up-to-date medical cost and earnings data.

Although the majority of total costs related to injury deaths were associated with unintentional injuries, substantial costs were also associated with suicide and homicide. The overall medical and work-loss costs associated with fatal injury differ considerably across demographic groups, intents, and mechanisms of injury. For example, males accounted for $75 \%$ of the costs of unintentional injury deaths, $86 \%$ of homicideassociated costs, and $82 \%$ of suicide-associated costs. Persons 
FIGURE 2. Distribution of lifetime medical and work-loss cost estimates for fatal injury, by mechanism and intent — United States, 2013

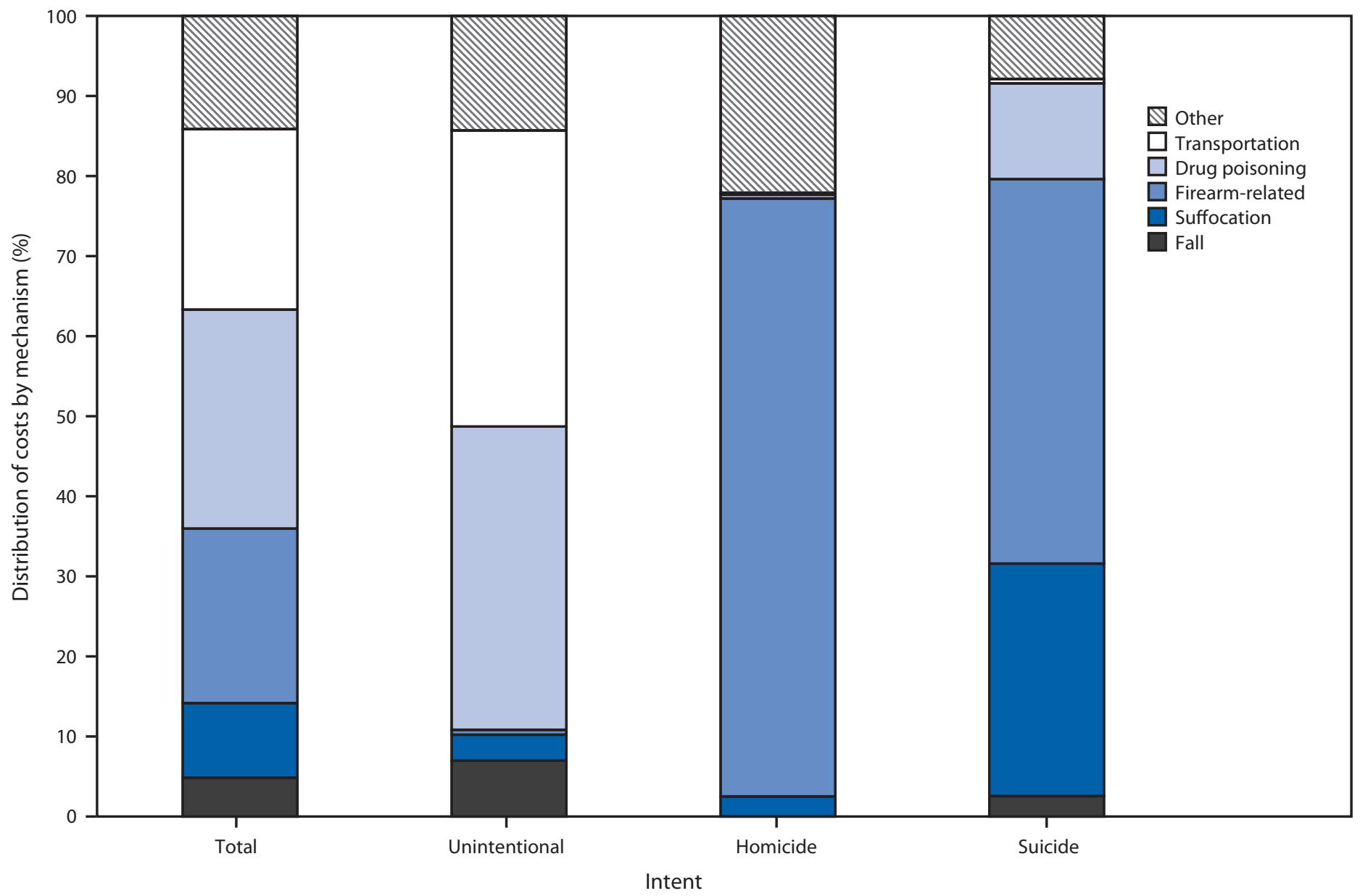

aged $15-44$ years accounted for $82 \%$ of homicide-associated costs, compared with $65 \%$ and $64 \%$ of suicide- and unintentional injury-associated costs, respectively. The higher burden of homicide at younger ages compared with other causes of injury death is reflected in the higher combined medical and work-loss cost per case for homicide.

The costs of injury deaths are not proportional to the rates of injury deaths because of the higher lifetime work-loss costs for persons who die at younger ages. These disparities largely result from differences in lost productivity, which are proportional to years of potential life lost. For example, persons aged $<65$ years accounted for $\$ 199.8$ billion (96\%) of the overall $\$ 208.3$ billion associated with fatal injuries. Although persons aged $\geq 65$ years accounted for $28 \%$ of all injury-associated deaths (and 35\% of all suicides), deaths in this age group accounted for only $1 \%$ (homicide) to $6 \%$ (unintentional injury) of costs related to injury deaths. Additionally, although the unintentional injury death rate for persons aged $\geq 65$ years was more than twice as high as for any other age group, only $6 \%$ of the unintentional costs were incurred by this age group, highlighting the relation between the cost of an injury death and years of potential life lost. Similarly, $18 \%$ of all suicides were among those aged $\geq 65$ years, yet $<3 \%$ of the suiciderelated costs were accounted for by this age group.

Although drug poisonings, transportation- and firearmrelated injuries, suffocation, and falls accounted for the greatest proportion of costs for all injury deaths, these proportions differed by intent. Firearm-related injuries accounted for most of the homicide-associated costs, and a large share of the cost of suicide, but $<1 \%$ of the costs of unintentional injuries. Drug poisonings, the leading mechanism of overall injury deaths, accounted for approximately $38 \%$ of the cost of unintentional deaths and $12 \%$ of the suicide-associated costs. More than $99 \%$ of transportation-related fatal injuries, which accounted for the second largest share of all costs, were associated with unintentional injury deaths.

The findings in this report are subject to at least four limitations. First, the costs measured account for medical costs and lost productivity associated with decedents. Other societal costs, including those associated with law enforcement, 


\section{Summary}

What is already known on this topic?

Injuries are a leading cause of death in the United States, particularly among adolescents and young adults. Intentional and unintentional injury-associated deaths result in a substantial economic burden. Injury and violence prevention strategies can save lives and reduce costs.

What is added by this report?

Cost of injury estimates were updated using improved methodology and the most recently available injury data. The total estimated lifetime medical and work-loss costs associated with fatal injuries in 2013 was $\$ 214$ billion. Males accounted for $78 \%$ of economic costs ( $\$ 166.7$ billion). Approximately $61 \%$ of the total costs were attributable to unintentional injuries (\$129.7 billion), followed by suicide ( $\$ 50.8$ billion [24\%]) and homicide ( $\$ 26.4$ billion [12\%]). Drug poisonings as a mechanism accounted for the largest share of injury costs (27\%), followed by transportation (23\%) and firearm-related injuries (22\%).

What are the implications for public health practice?

Injury deaths created a substantial economic burden in the United States during 2013. Understanding the causes and mechanisms of injury death that created the largest share of this burden, such as drug overdoses, and understanding disparities among affected groups can inform public health prevention efforts.

prosecution, and corrections, as well as the pain and suffering of family members, were not considered. Second, intent of fatal injury, as determined from the manner of death assigned on death certificates by coroners or medical examiners, can differ across jurisdictions (7). Finally, work-loss costs were assigned using the mean earnings of the general population by sex and specific age groups. If the mean earnings of persons who die from injuries differ from those of the general population, the estimates might be higher or lower than the actual lost earnings.

Injury prevention programs, strategies, and practices can reduce risks for deaths, enhance protection at the individual, relationship, neighborhood, and societal levels, and substantially reduce the costs identified in this report. Numerous strategies have demonstrated the potential for preventing different causes and mechanisms of injury. For example, street outreach programs that effectively mediate conflicts in high-crime communities have shown promise in reducing firearm-related violence (8). Information about the cost-effectiveness of injury prevention strategies is also expanding. Child safety seat laws and sobriety checkpoints offer net cost savings, with medical and other resource costs saved that exceed implementation and maintenance costs (9). These current estimates of the economic burden of fatal injuries can used by decision makers to compare the costs of implementing prevention strategies with the cost that might be avoided by preventing injuries.

${ }^{1}$ Division of Analysis, Research and Practice Integration, National Center for Injury Prevention and Control, CDC; ${ }^{2}$ Division of Violence Prevention, National Center for Injury Prevention and Control, CDC; ${ }^{3}$ Division of Unintentional Injury Prevention, National Center for Injury Prevention and Control, CDC.

Corresponding author: Curtis Florence, cflorence@cdc.gov, 770-488-1398.

\section{References}

1. CDC. Web-Based Injury Statistics Query and Reporting System (WISQARS). Available at http://www.cdc.gov/injury/wisqars.

2. Finkelstein EA, Corso PS, Miller TR, et al. The incidence and economic burden of injury in the United States. New York, NY: Oxford University Press; 2006.

3. Florence C, Haegerich T, Simon T, et al. Estimated lifetime medical and work-loss costs of emergency department-treated nonfatal injuries-United States, 2013. MMWR Morb Mortal Wkly Rep 2015;64:1078-82.

4. Lawrence BA, Miller TA. Medical and work loss cost estimation methods for the WISQARS cost of injury module. Available at http://www.pire. org/documents/WisqarsCostMethods.pdf.

5. Baker SP, Hu G, Wilcox HC, Baker TD. Increase in suicide by hanging/ suffocation in the U.S., 2000-2010. Am J Prev Med 2013;44:146-9.

6. National Center for Statistics and Analysis. 2013 motor vehicle crashes: overview. Available at http://www-nrd.nhtsa.dot.gov/Pubs/812101.pdf.

7. Breiding MJ, Wiersema B. Variability of undetermined manner of death classification in the US. Inj Prev 2006;12(Suppl 2):ii49-54.

8. Webster DW, Whitehill JM, Vernick JS, Curriero FC. Effects of Baltimore's Safe Streets Program on gun violence: a replication of Chicago's CeaseFire Program. J Urban Health 2013;90:27-40.

9. Miller T, Finkelstein E, Zaloshnja E, Hendrie D. The cost of child and adolescent injuries and the savings from prevention, in Injury prevention for children and adolescents: research, practice, and advocacy. Liller K, ed. Washington, DC: American Public Health Association; 2012:15-64. 


\title{
Estimated Lifetime Medical and Work-Loss Costs of Emergency Department- Treated Nonfatal Injuries — United States, 2013
}

\author{
Curtis Florence, $\mathrm{PhD}^{1}$; Tamara Haegerich, $\mathrm{PhD}^{2}$; Thomas Simon, $\mathrm{PhD}^{3}$; Chao Zhou, $\mathrm{PhD}^{1}$; Feijun Luo, $\mathrm{PhD}^{1}$
}

A large number of nonfatal injuries are treated in U.S. emergency departments (EDs) every year. CDC's National Center for Health Statistics estimates that approximately $29 \%$ of all ED visits in 2010 were for injuries (1). To assess the economic impact of ED-treated injuries, CDC examined injury data from the National Electronic Injury Surveillance System-All Injury Program (NEISS-AIP) (2) for 2013, as well as injury-related lifetime medical and work-loss costs from the Web-Based Injury Statistics Query and Reporting System (WISQARS). NEISS-AIP collects data from a nationally representative sample of EDs, using specific guidelines for recording the primary diagnosis and mechanism of injury. Number of injuries, crude- and age-specific injury rates, and total lifetime work-loss costs and medical costs were calculated for ED-treated injuries, stratified by sex, age groups, and intent and mechanism of injury. ED-treated injuries were further classified as those that were subsequently hospitalized or treated and released. The rate of hospitalized injuries was 950.8 per 100,000 , and the rate of treated and released injuries was $8,549.8$ per 100,000. Combined medical and work-loss costs for all ED-treated injuries (both hospitalized and treated and released) were $\$ 456.9$ billion, or approximately $68 \%$ of the total costs of $\$ 671$ billion associated with all fatal and ED-treated injuries. The substantial economic burden associated with nonfatal injuries underscores the need for effective prevention strategies.

Numbers of ED-treated injuries, rates, and lifetime cost estimates by age and sex of the patient and by mechanism and intent of injury were analyzed using WISQARS (3). Rates were calculated using the U.S. Census Bureau's bridged race population estimates for 2013. Lifetime medical and work-loss costs were calculated from average costs of treating nonfatal injuries and earnings in 2010, adjusted to 2013 prices. Lifetime work-loss is the estimated wages lost because of time away from work while recovering from the injury, and the loss of income incurred for injuries that lead to permanent disability. For each ED-treated injury record, lifetime work-loss costs and medical costs were assigned using the age and sex of the injured person, along with the injury diagnosis and mechanism (4). Work-loss and medical costs for nonfatal injuries were developed from various sources, including days of work missed because of injury, from the Agency for Healthcare Research and Quality's (AHRQ) Medical Expenditure Panel Survey; hospital costs, from the Health Care Cost and Utilization Project; earnings data, from the U.S. Census Bureau's Current Population Survey; and life expectancy data, from CDC's National Center for Health Statistics. Number of injuries, rates, and total lifetime medical and work-loss costs were estimated for 2013, stratified by sex, age and intent of injury. Differences by race and ethnicity were not examined because those data are not available in the WISQARS nonfatal injury reports. The distribution of costs by mechanism of injury and ED discharge disposition of treatment (i.e., hospitalized or treated and released) was also assessed for seven selected mechanisms. Finally, the costs of ED-treated nonfatal injuries were compared with those of fatal injuries presented in another $M M W R$ report (5).

For all ED-treated nonfatal injuries, the total costs were $\$ 456.9$ billion; $63 \%$ of these costs were for hospitalized injuries, for which the total estimated lifetime medical and work-loss costs were $\$ 289.7$ billion (Table 1). Approximately $65 \%$ of these costs were accounted for by males; these costs were also concentrated in the adult population, with more than three quarters of the cost being for persons aged $\geq 25$ years. Unintentional injuries accounted for $\$ 253.5$ billion in lifetime costs, or about $87 \%$ of costs for hospitalized injuries. Assault injuries and self-harm injuries (defined as an injury or poisoning resulting from a deliberate violent act inflicted on oneself) accounted for $\$ 26.4$ billion and $\$ 11.3$ billion of lifetime costs, respectively. Approximately $85 \%$ of costs for hospitalized assault injuries were borne by males ( $\$ 22.5$ billion), whereas costs for hospitalized self-harm injuries were more similar among males ( $\$ 6.5$ billion) and females ( $\$ 4.7$ billion). Costs for hospitalized violent injuries were concentrated among adults aged $15-44$ years, with $72 \%$ of costs for assaults and $67 \%$ of self-harm costs accounted for by these age groups. In contrast, adults aged $\geq 45$ years accounted for $59 \%$ of costs associated with hospitalized injuries that were unintentional.

Total estimated costs for injuries for which patients were treated and released were $\$ 167.1$ billion (Table 2). Approximately $58 \%$ of these costs were accounted for by males ( $\$ 96.2$ billion), and $71 \%$ for persons aged $<45$ years. A very large share of these costs ( $\$ 156.1$ billion [93\%]) was for unintentional injuries. Assault injuries and self-harm injuries accounted for $\$ 9.8$ billion and $\$ 627$ million in costs, respectively. Males accounted for about two thirds of assault 
TABLE 1. Hospitalized* nonfatal injuries, rates per 100,000 population, and estimated lifetime medical and work-loss costs, by sex, age group, and intent — United States, 2013

\begin{tabular}{|c|c|c|c|c|c|c|c|c|}
\hline \multirow[b]{2}{*}{ Intent } & \multirow[b]{2}{*}{ Total } & \multicolumn{2}{|c|}{ Sex } & \multicolumn{5}{|c|}{ Age group (yrs) } \\
\hline & & Male & Female & $0-14$ & $15-24$ & $25-44$ & $45-64$ & $\geq 65$ \\
\hline \multicolumn{9}{|l|}{ All intents*† } \\
\hline No. of injuries & $3,005,772$ & $1,639,305$ & $1,366,326$ & 189,400 & 337,789 & 678,465 & 829,903 & 967,066 \\
\hline Rate $^{\S}$ & 950.81 & $1,053.19$ & 851.41 & 310.04 & 768.50 & 814.51 & 998.87 & $2,163.26$ \\
\hline Costs" & 289,730 & 191,283 & 101,022 & 22,352 & 38,106 & 75,308 & 87,932 & 69,783 \\
\hline \multicolumn{9}{|l|}{ Unintentional } \\
\hline No. of injuries & $2,486,337$ & $1,351,321$ & $1,134,950$ & 164,271 & 196,256 & 471,906 & 699,926 & 952,138 \\
\hline Rate $^{\S}$ & 786.49 & 868.17 & 707.23 & 268.90 & 446.50 & 566.53 & 842.43 & $2,129.87$ \\
\hline Costs & 253,549 & 162,965 & 93,001 & 20,125 & 27,636 & 61,344 & 80,462 & 69,199 \\
\hline \multicolumn{9}{|l|}{ Assault } \\
\hline No. of injuries & 169,076 & 134,952 & 34,115 & 6,659 & 47,458 & 73,258 & 36,120 & 4,388 \\
\hline Rate $^{\S}$ & 53.48 & 86.70 & 21.26 & 10.90 & 107.97 & 87.95 & 43.47 & 9.81 \\
\hline Costs" & 26,366 & 22,529 & 3,681 & 906 & 7,113 & 11,962 & 5,728 & 462 \\
\hline \multicolumn{9}{|l|}{ Self-harm } \\
\hline No. of injuries & 344,914 & 147,871 & 196,977 & 18,461 & 92,959 & 129,876 & 93,121 & 10,404 \\
\hline Rate $^{\S}$ & 109.11 & 95.00 & 122.74 & 30.22 & 211.49 & 155.92 & 112.08 & 23.27 \\
\hline Costs 9 & 11,320 & 6,522 & 4,728 & 595 & 3,212 & 4,373 & 2,800 & 317 \\
\hline
\end{tabular}

* Includes nonfatal injuries initially treated in a hospital emergency department that resulted in hospitalization or transfer for specialized medical care.

${ }^{\dagger}$ All intents include legal intervention. Assault, self-harm, and legal intervention include cases that are confirmed or suspected. All other cases are considered unintentional.

$\S$ Injuries per 100,000 population.

II In millions of 2013 U.S. dollars. Cost estimates were computed from average lifetime work-loss and medical costs by mechanism and intent of injury. The base year for average costs was 2010. Base year costs were indexed to 2013 prices and applied to 2013 emergency department-treated injury counts. Lifetime medical costs refer to the medical costs associated with the injury event.

TABLE 2. Treated and released* nonfatal injuries, rates per 100,000 population, and estimated lifetime medical and work-loss costs (in millions of dollars), by sex, age group, and intent — United States, 2013

\begin{tabular}{|c|c|c|c|c|c|c|c|c|}
\hline \multirow[b]{2}{*}{ Intent } & \multirow[b]{2}{*}{ Total } & \multicolumn{2}{|c|}{ Sex } & \multicolumn{5}{|c|}{ Age group (yrs) } \\
\hline & & Male & Female & $0-14$ & $15-24$ & $25-44$ & $45-64$ & $\geq 65$ \\
\hline \multicolumn{9}{|l|}{ All intents*† } \\
\hline No. of injuries & $27,028,247$ & $14,358,379$ & $12,669,537$ & $5,819,455$ & $5,014,247$ & $7,580,392$ & $5,665,770$ & $2,947,418$ \\
\hline Rate ${ }^{\S}$ & $8,549.76$ & $9,224.69$ & $7,894.91$ & $9,526.17$ & $11,407.84$ & $9,100.41$ & $6,819.33$ & $6,593.18$ \\
\hline Costs" & 167,135 & 96,233 & 70,701 & 36,750 & 30,348 & 50,749 & 35,699 & 13,281 \\
\hline \multicolumn{9}{|l|}{ Unintentional } \\
\hline No. of injuries & $25,407,794$ & $13,418,964$ & $11,988,499$ & $5,681,198$ & $4,504,264$ & $6,909,368$ & $5,386,913$ & $2,925,179$ \\
\hline Rate $^{\S}$ & $8,037.16$ & $8,621.15$ & $7,470.53$ & $9,299.85$ & $10,247.58$ & $8,294.83$ & $6,483.70$ & $6,543.43$ \\
\hline Costs" & 156,087 & 89,042 & 66,883 & 35,903 & 26,850 & 45,995 & 33,869 & 13,178 \\
\hline \multicolumn{9}{|l|}{ Assault } \\
\hline No. of injuries & $1,398,931$ & 816,536 & 582,394 & 120,616 & 434,671 & 584,023 & 239,462 & 20,091 \\
\hline Rate $^{\S}$ & 442.52 & 524.59 & 362.91 & 197.44 & 988.91 & 701.13 & 288.22 & 44.94 \\
\hline Costs & 9,753 & 6,358 & 3,371 & 770 & 3,051 & 4,235 & 1,601 & 93 \\
\hline \multicolumn{9}{|l|}{ Self-harm } \\
\hline No. of injuries & 130,650 & 46,992 & 83,658 & 15,766 & 48,818 & 41,825 & 22,819 & 1,422 \\
\hline Rate $^{\S}$ & 41.33 & 30.19 & 52.13 & 25.81 & 111.07 & 50.21 & 27.47 & 3.18 \\
\hline Costs" & 627 & 245 & 377 & 61 & 218 & 214 & 121 & 7 \\
\hline
\end{tabular}

Sources: National Electronic Injury Surveillance System-All Injury Program (NEISS-AIP) for injury rates, disposition, and mechanism. Pacific Institute for Research and Evaluation for unit cost estimates. U.S. Census Bureau for population estimates. Numbers and rates computed using WISQARS (http://www.cdc.gov/injury/wisqars).

* Includes nonfatal injuries for persons initially treated in a hospital emergency department and then released.

${ }^{\dagger}$ All intents include legal intervention. Assault, self-harm, and legal intervention include cases that are confirmed or suspected. All other cases are considered unintentional.

$\S$ Injuries per 100,000 population.

"In millions of 2013 U.S. dollars. Cost estimates were computed from average lifetime work-loss and medical costs by mechanism and intent of injury. The base year for average costs was 2010. Base year costs were indexed to 2013 prices and applied to 2013 emergency department-treated injury counts. Lifetime medical costs refer to the medical costs associated with the injury event. 


\section{Summary}

What is already known on this topic?

Each year, approximately 3 million persons are hospitalized and 27 million are treated and released in emergency departments (EDs) in the United States because of violence and unintentional injuries. Medical and work-loss costs associated with these injuries create a substantial economic burden for the health care system and the general public.

What is added by this report?

During 2013, the rate of nonfatal injuries treated in U.S. hospital EDs that resulted in hospitalization was 951 per 100,000, and the rate of nonfatal injuries that were treated and released was 8,549 per 100,000 . Nonfatal injuries accounted for approximately $\$ 456$ billion in medical and work-loss costs. The vast majority of ED-treated nonfatal injuries were unintentional. The majority of medical and work-loss costs associated with ED-treated nonfatal injuries were from falls (37\% of costs) and transportation-related injuries ( $21 \%$ of costs).

What are the implications for public health practice?

Injury and violence prevention strategies can reduce a substantial source of morbidity and financial burden in the United States. Understanding how the cost burden is distributed across different mechanisms and segments of the population can allow prevention interventions to be targeted where they will have the greatest impact. The concentration of costs from falls (primarily among older adults) and transportation-related injuries suggests that a substantial proportion of costs can be avoided by implementation of prevention strategies that address these mechanisms and age groups.

costs ( $\$ 6.4$ billion), whereas females accounted for $60 \%$ of the self-harm costs ( $\$ 377$ million). Rates for nonfatal treated and released injuries from assaults and self-harm were highest among those aged 15-24 years, followed by those aged 25-44 years. Persons aged 15-44 years accounted for a large share of assault (83\%) and self-harm costs (79\%), whereas costs for unintentional treated and released injuries were more evenly distributed among age groups.

Although unintentional injuries account for a large majority of nonfatal injuries and their associated costs, intentional injuries are more costly on a per case basis (Figure 1). Overall, the mean medical and work-loss cost for an ED-treated nonfatal injury (including both hospitalized patients and patients treated and released) was $\$ 15,211$; among unintentional injuries, the mean cost was $\$ 14,685$, whereas the mean cost of an assault injury was $\$ 23,034$. Self-harm injuries were the most costly on a per case basis $(\$ 25,121)$. Assaults and selfharm have considerably higher lifetime medical care costs, and assaults have higher work-loss costs than unintentional injuries.

Lifetime costs for ED-treated injuries were associated with a range of injury mechanisms (Figure 2), and in many cases,
FIGURE 1. Mean medical and work-loss costs per case of emergency department-treated nonfatal injury, by intent* — United States, 2013

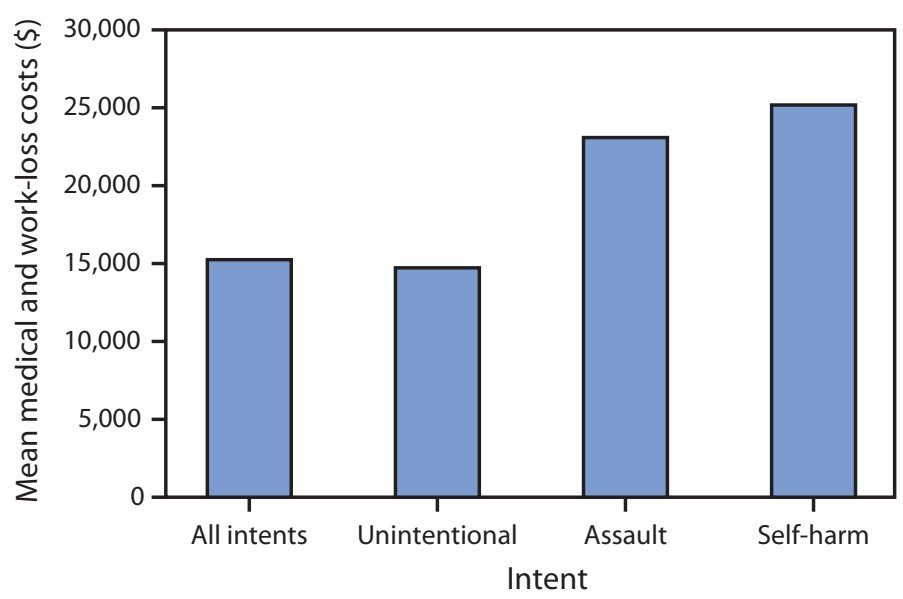

* All intents category includes legal intervention. Assault, self-harm, and legal intervention are cases that are confirmed or suspected. All other cases are considered unintentional.

these mechanisms differed from those that accounted for fatal injury costs (5). For all ED-treated nonfatal injuries, $37 \%$ of costs were associated with injuries from falls, and $21 \%$ from transportation-related injuries. All poisonings accounted for only $2.6 \%$ of nonfatal injury costs; however, among fatal injuries (5), drug poisonings, a subset of all poisonings, accounted for the highest percentage of costs (27.4\%) (5). Although firearm-related injuries accounted for approximately one fifth of costs associated with fatal injuries (5), they represent slightly more than $1 \%$ of costs from nonfatal injuries. Hospitalized injury costs were primarily associated with falls (41\%) and transportation $(25 \%)$. A large share of costs related to injuries that were treated and released were also associated with falls $(30 \%)$, whereas other mechanisms, such as overexertion, accounted for a higher percentage of costs than for hospitalized injuries (14\%).

\section{Discussion}

In addition to the recognized health, psychological, emotional, and social consequences of injury, ED-treated nonfatal injuries resulted in substantial costs for the U.S. health care system, as well as substantial work-loss costs in 2013; these costs provide a strong incentive to prevent injury. Although almost $90 \%$ of all ED-treated injury costs were associated with unintentional injuries, the costs per case were $57 \%$ higher for injuries resulting from assaults and $71 \%$ higher for injuries resulting from self-harm than for unintentional injuries.

Various mechanisms account for nonfatal injury costs; some, such as falls and transportation-related injuries (primarily motor vehicle crashes), account for large shares of nonfatal and fatal injury costs; whereas others are differentially distributed. 
FIGURE 2. Distribution of lifetime medical and work-loss cost estimates for nonfatal injury, by mechanism and disposition — United States, 2013

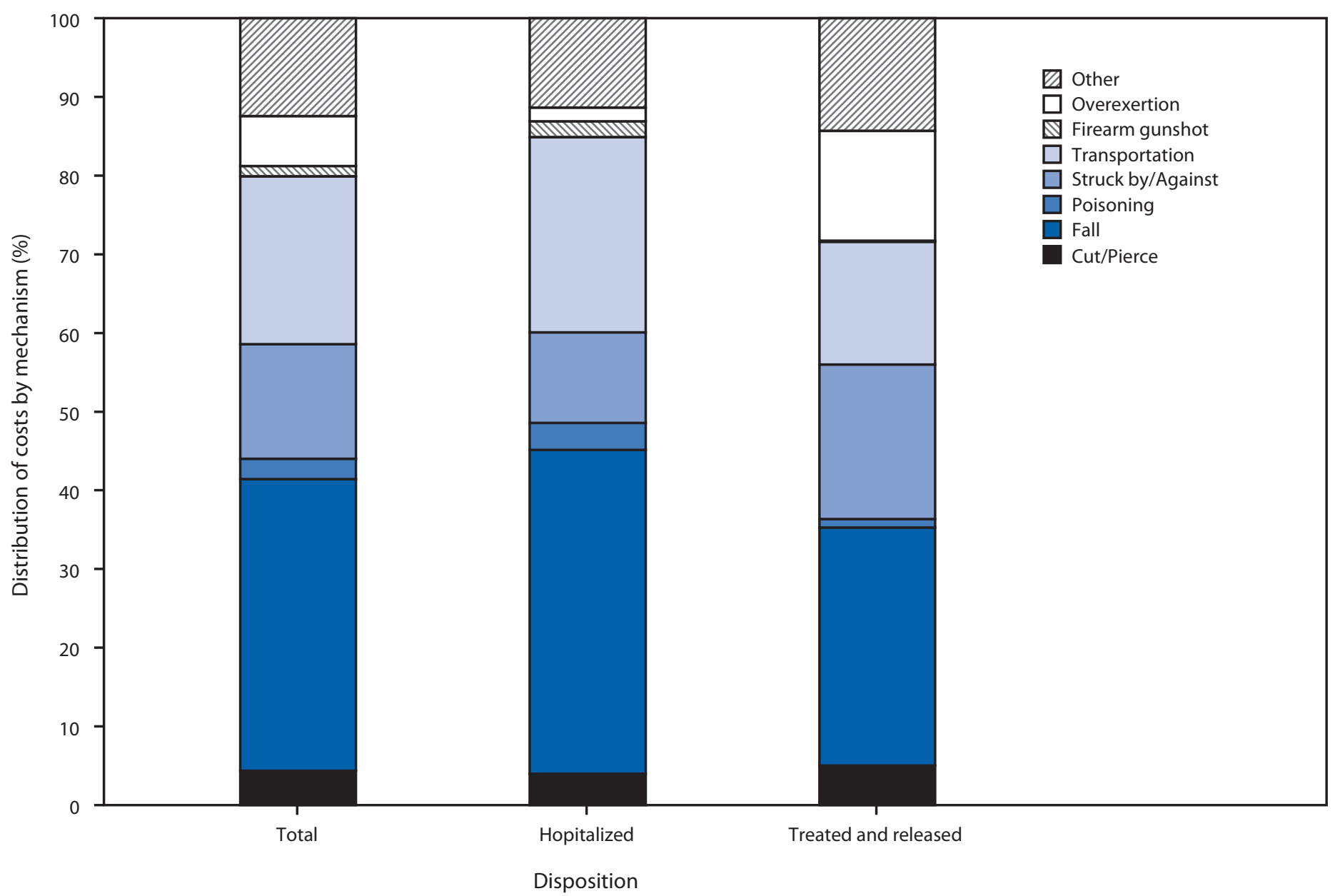

Falls account for approximately one third of all (treated and released and hospitalized) nonfatal medical and work-loss costs. Falls were also the fifth leading mechanism for fatal injury costs, so effective prevention of fall injuries, such as strength and balancing exercises for older adults, could result in a substantial reduction in lifetime medical and work-loss costs (5). Transportation-related injury (primarily motor vehicle crashes), a leading contributor to fatal injury costs, also accounts for the second largest share of nonfatal injury costs (5). Some mechanisms that account for a large share of fatal injury costs, such as firearms and drug poisonings, account for a relatively small share of nonfatal injury costs (5), likely a consequence of their higher lethality.

The findings in this report are subject to at least three limitations. First, the costs measured account for medical costs for physical injury only and lost productivity associated with nonfatal injuries initially treated in hospital EDs. Costs of injuries treated in other health care settings, or injuries that were not medically treated, were not ascertained. Second, additional costs (e.g., for mental health or psychological treatment and costs for the criminal justice and emergency response systems) were not considered, nor were costs that might be incurred years after the initial injury, as in the case of child maltreatment $(\sigma)$. Therefore, these estimates likely represent an underestimate of the complete cost of injury. Finally, intent of injury and mechanism were assigned by trained coders based on brief narratives abstracted from patients' medical records for which the level of detail on circumstances varied. Inaccuracies in the abstraction and coding process might have affected the distribution of cost by intent and mechanism.

Although nonfatal injuries treated in EDs are common and costly, appropriate implementation of evidence-based strategies can reduce nonfatal injuries from the mechanisms that lead to the greatest cost burden. For example, primary seat belt laws, motorcycle helmet laws, sobriety checkpoints, and alcohol interlocks are effective in preventing motor vehicle-related injuries and can produce substantial economic benefits that greatly exceed the implementation costs (7). The relatively high rate of injuries from assaults and self-harm among adolescents and young adults underscores the need for early prevention 
strategies that take advantage of the best available evidence to enhance youths' skills, family relationships, and social environments to reduce risk for violence-related injuries. One example is Life Skills Training, a middle school classroom-based program to reduce substance use, which is a risk factor for violent behavior $(8,9)$. Finally, the ED might also be a useful setting for implementing prevention. Studies of some screening and brief intervention programs for reducing excessive alcohol use, which is a risk factor for both unintentional and violent injuries, have shown that this intervention can reduce the likelihood of a subsequent visit to the ED for injury or violence-related causes (10). Expanded implementation of evidence-based programs and policies to prevent injuries and violence can reduce not only the pain and suffering of victims but also the considerable societal costs.

${ }^{1}$ Division of Analysis, Research and Practice Integration, National Center for Injury Prevention and Control, CDC; ${ }^{2}$ Division of Violence Prevention, National Center for Injury Prevention and Control, CDC; ${ }^{3}$ Division of Unintentional Injury Prevention, National Center for Injury Prevention and Control, CDC.

Corresponding author: Curtis Florence, cflorence@cdc.gov, 770-488-1398.

\section{References}

1. CDC. National Hospital Ambulatory Medical Care Survey: 2010 emergency department summary tables. Available at http://www.cdc. gov/nchs/data/ahcd/nhamcs_emergency/2010_ed_web_tables.pdf.

2. US Consumer Product Safety Commission National Electronic Injury Surveillance System. Available at http://www.cpsc.gov/en/Research-Statistics/NEISS-Injury-Data.

3. CDC. Nonfatal injury data. Available at http://www.cdc.gov/injury/ wisqars/nonfatal.html.

4. Lawrence BA, Miller TA. Medical and work-loss cost estimation methods for the WISQARS Cost of Injury module. Available at http://www.pire. org/documents/WisqarsCostMethods.pdf.

5. Florence C, Simon T, Haegerich T, et al. Lifetime medical and work-loss costs of fatal injuries-United States, 2013. MMWR Morb Mortal Wkly Rep 2015;64:1074-7.

6. Fang X, Brown DS, Florence CS, Mercy JA. The economic burden of child maltreatment in the United States and implications for prevention. Child Abuse Negl 2012;36:156-65.

7. Preusser DF, Williams AF, Nichols JL, Tison J, Chaudhary NK. Effectiveness of behavioral highway safety countermeasures. Available at http://onlinepubs.trb.org/onlinepubs/nchrp/nchrp_rpt_622.pdf.

8. Center for the Study and Prevention of Violence. Blueprints for healthy youth development. Available at http://www.blueprintsprograms.com.

9. Substance Abuse and Mental Health Services Administration. National Registry of Evidence-Based Programs and Practices. Available at http:// www.nrepp.samhsa.gov.

10. Mello MJ, Nirenberg TD, Longabaugh R, et al. Emergency department brief motivational interventions for alcohol with motor vehicle crash patients. Ann Emerg Med 2005;45:620-5. 


\title{
Ebola Virus Disease in Health Care Workers — Guinea, 2014
}

\author{
Margaret Grinnell ${ }^{1}$; Meredith G. Dixon, $\mathrm{MD}^{2}$; Monica Patton, $\mathrm{MD}^{3}$; David Fitter, MD4; Pépé Bilivogui, MD5; Candice Johnson, PhD ${ }^{6}$; \\ Ellen Dotson, DSc 7 ; Boubacar Diallo, $\mathrm{MD}^{8}$; Guenael Rodier, $\mathrm{MD}^{8}$; Pratima Raghunathan, $\mathrm{PhD}^{2}$
}

An outbreak of Ebola virus disease (Ebola) began in Guinea in December 2013 and has continued through September 2015 (1). Health care workers (HCWs) in West Africa are at high risk for Ebola infection owing to lack of appropriate triage procedures, insufficient equipment, and inadequate infection control practices $(2,3)$. To characterize recent epidemiology of Ebola infections among HCWs in Guinea, national Viral Hemorrhagic Fever (VHF) surveillance data were analyzed for HCW cases reported during January 1-December 31, 2014. During 2014, a total of 162 (7.9\%) of 2,210 laboratoryconfirmed or probable Ebola cases among Guinean adults aged $\geq 15$ years occurred among HCWs, resulting in an incidence of Ebola infection among HCWs 42.2 times higher than among non-HCWs. The disproportionate burden of Ebola infection among HCWs taxes an already stressed health infrastructure, underscoring the need for increased understanding of transmission among HCWs and improved infection prevention and control measures to prevent Ebola infection among HCWs.

Surveillance data from the national VHF database were analyzed for cases with a notification date in 2014. Using case definitions described previously (4), a standardized case investigation form was completed for every suspected, probable, or confirmed Ebola case that included age, sex, location of residence, occupation, symptom onset date, whether or not the patient was isolated in an Ebola treatment unit (ETU), and clinical outcome. Any person working in nonhousehold settings and who had contact with patients or patient waste was considered to be an HCW, including, but not limited to, doctors, nurses, midwives, hospital cleaners, ambulance drivers, laboratory workers, and ancillary health care staff. Traditional healers were not included. Only confirmed and probable Ebola cases in persons aged $\geq 15$ years were included in the analysis. Incidence of Ebola infection was calculated using population denominators from the preliminary 2014 Guinea census and HCW denominators from the Guinea Ministry of Health $(\mathrm{MOH})(5,6)$. Population denominators for persons aged $\geq 15$ years were calculated assuming that $58 \%$ of the total population was aged $\geq 15$ years ( 7 ). Outside of the capital Conakry, Guinea is divided into 33 administrative regions called prefectures. Geographic trends were analyzed by prefecture, with cases assigned to the location of the patient's permanent residence. Characteristics of HCW and non-HCW cases were compared using Chi-square tests; p-values $<0.05$ were considered statistically significant.
In 2014, a total of $162(7.9 \%)$ of 2,210 laboratory-confirmed or probable Ebola cases reported from Guinea in persons aged $\geq 15$ years occurred among HCWs. With an estimated 11,529 HCWs in Guinea and a national population of 6.15 million persons aged $\geq 15$ years, the incidence of laboratory-confirmed or probable Ebola infections among HCWs in Guinea was 140.5 per 10,000 HCWs, compared with 3.3 per 10,000 nonHCWs aged $\geq 15$ years (relative risk $=42.2 ; 95 \%$ confidence interval $=36.0-49.5$ ).

Cases of Ebola infections among HCWs during this outbreak were first reported in January 2014 (2014 notification week 4). The highest number of Ebola case notifications in HCWs in Guinea in a single week occurred during week 51 with 15 cases (Figure 1). This also corresponded to the week with the highest number of total Ebola cases (HCW and nonHCW) in Guinea during 2014.

During 2014, Ebola cases among HCWs were reported in Conakry and 17 (52\%) of the 33 prefectures in Guinea (Figure 2). HCW case counts were highest in Conakry (64 cases) and N'Zérékoré (17 cases). HCW cases made up the largest percentage of total cases in Dabola (33.3\%), Yomou (20.0\%), and Conakry (19.6\%).

Among persons with confirmed and probable Ebola, HCWs were more likely to be male than non-HCWs (Table). The majority of Ebola cases among both HCWs and non-HCWs occurred among persons aged 15-49 years. The fatality rate was higher among non-HCWs. Among Ebola patients, nonHCWs were also more likely to be identified in the community after their death. Although HCWs with Ebola were more likely than non-HCW Ebola patients to be isolated in an ETU, the time between symptom onset and isolation was similar for HCWs (4.9 days) and non-HCWs (5.2 days); however, time from symptom onset until isolation was missing for 38\% of non-HCWs and $20 \%$ of HCWs. Data on Ebola exposures were not complete for all Ebola patients; among Ebola patients with complete information, HCWs were significantly less likely to report attendance at a funeral than were non-HCWs and were also less likely to report any contact with a person known to have Ebola than were non-HCWs.

The most common occupations of HCWs with Ebola were doctor, nurse, and health technician (Table); these accounted for almost two thirds of occupations of HCWs with Ebola. Among Guinean HCWs, incidence of Ebola infection was highest among laboratory technicians $(34.7$ per 1,000$)$ and 
FIGURE 1. Number of confirmed and probable cases of Ebola virus disease per 10,000 persons among health care workers and non-health care workers aged $\geq 15$ years, by notification week - Guinea, 2014

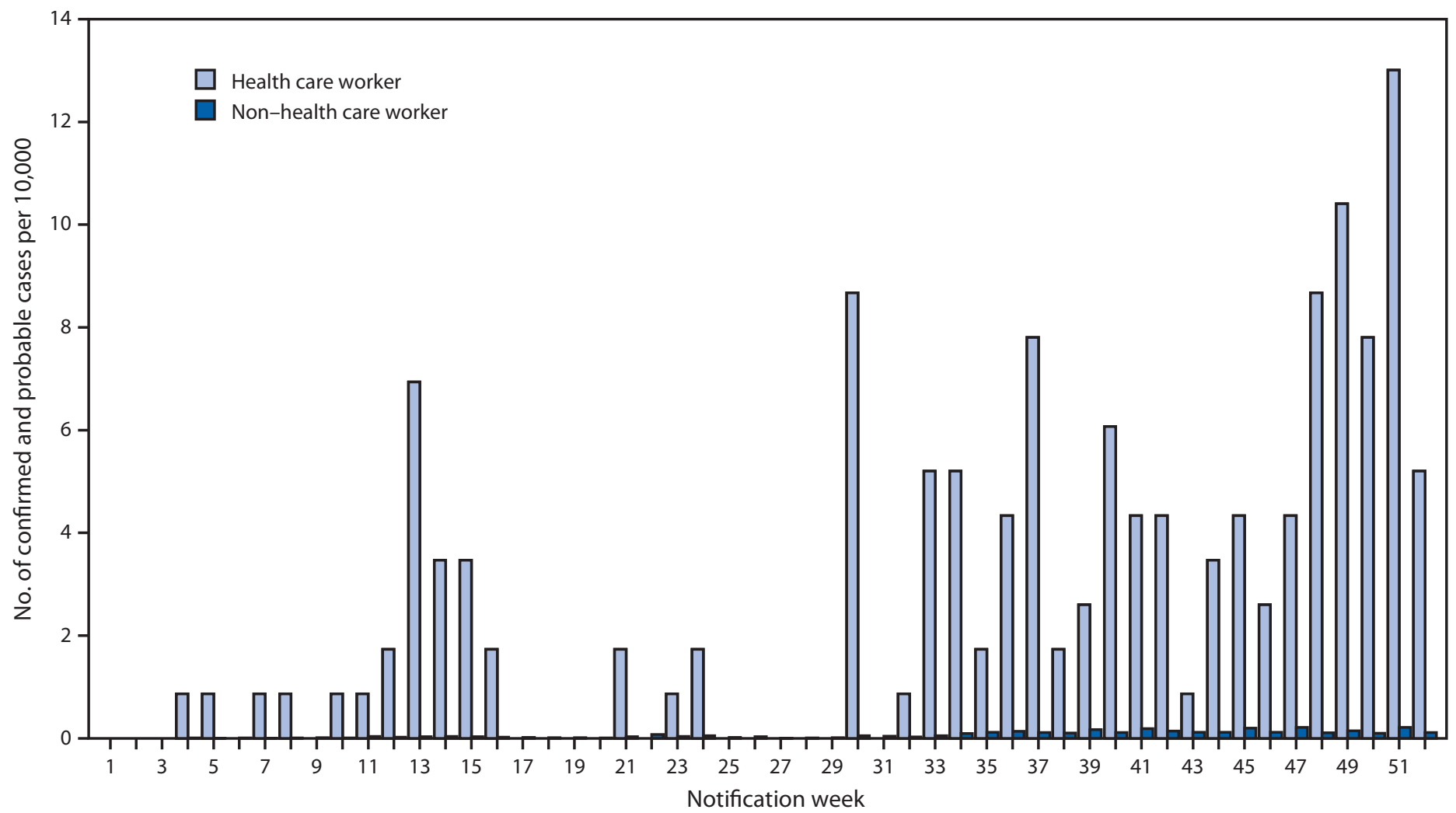

doctors (26.6 per 1,000), followed by midwives ( 8.7 per 1,000) and nurses $(5.5$ per 1,000). Place of work was known for 114 (70\%) HCWs with Ebola; among those, only one worked at an ETU.

\section{Discussion}

In 2014, Guinean HCWs had an incidence of Ebola infection 42.2 times higher than that of non-HCWs. Doctors and male HCWs were more affected than HCWs in other roles and female HCWs. Among Ebola cases, HCW patients were less likely than non-HCW patients to report risk factors such as funeral attendance or contact with a person know to have Ebola, although data completeness was poor for these measures.

Higher incidence of Ebola infection among HCWs than non-HCWs has also been reported in Sierra Leone and Liberia, two neighboring countries with intense Ebola transmission in 2014 (3). In Guinea, doctors represented the largest proportion of Ebola cases among HCWs, unlike Liberia, where nurses were the most affected group (8). In settings with an inadequate health infrastructure, high incidence of Ebola infection among HCWs not only limits the country's ability to respond to the Ebola outbreak, but also limits its baseline ability to address routine health care needs.

\section{Summary}

What is already known on this topic?

Health care workers (HCWs) are at high risk for infection in outbreaks of Ebola virus disease (Ebola). Ebola infections in $\mathrm{HCW}$ can be reduced through thorough appropriate triage and adherence to good infection prevention and control practices.

What is added by this report?

During 2014, a total of 162 (7.9\%) of 2,210 laboratory-confirmed or probable Ebola cases among Guineans aged $\geq 15$ years occurred among HCWs, resulting in a cumulative incidence of Ebola infection among HCWs 42.2 times higher than among non-HCWs. Doctors and male HCWs were disproportionally affected compared with HCWs in other roles and female HCWs.

What are the implications for public health practice?

Ebola infections among HCWs are an important focus area for Ebola outbreak response, and thorough investigation of cases in HCWs is important to better understand sources of exposure, reasons for delay in isolation once symptoms develop, particular job tasks that increase the risk for infection, and reasons that particular groups, such as males and doctors, are disproportionally affected. An increased understanding of HCW risks for infection along with continuous infection prevention and control efforts are necessary to prevent Ebola infection in this high-risk occupational group. 
FIGURE 2. Geographic distribution of confirmed and probable Ebola virus disease (Ebola) cases among health care workers aged $\geq 15$ years - Guinea, 2014

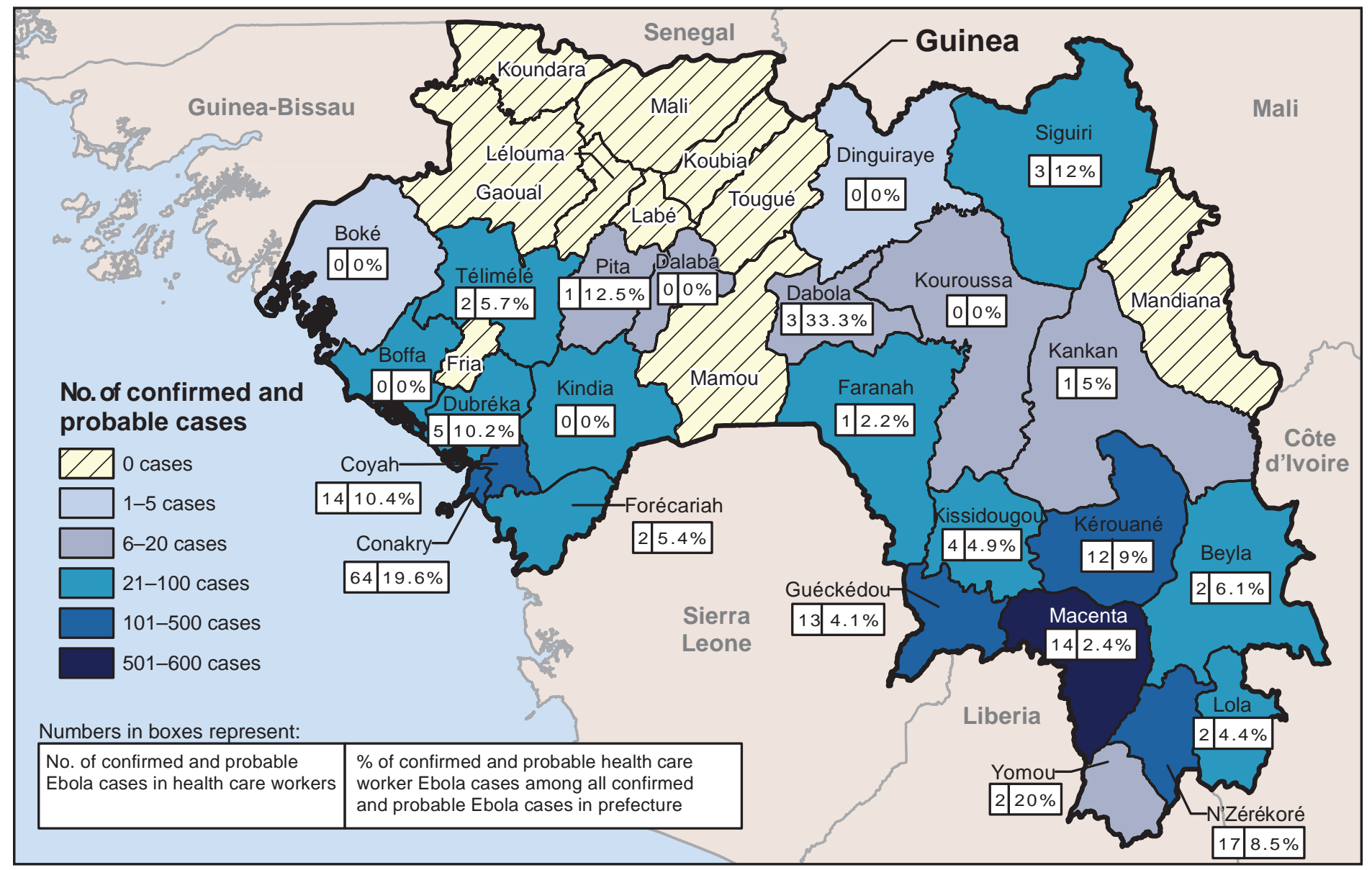

This evaluation found that $27 \%$ of Ebola infections among HCWs in Guinea occurred among doctors, who account for $14 \%$ of the health care workforce (5). Although no significant difference in infection rates among HCWs by sex has been reported from Sierra Leone or Liberia $(3,8)$, male HCWs in Guinea appear to be at increased risk compared with female HCWs; in this evaluation, $75 \%$ of Ebola infections among HCWs occurred among males. Information on a subset of HCWs employed by the Guinea $\mathrm{MOH}$ indicates that males represent $46.4 \%$ of the overall health care workforce and $67.4 \%$ of doctors (Guinea $\mathrm{MOH}$, unpublished data, September 2015). The male predominance in Ebola infections among HCWs in not completely explained by the predominance of doctors. When stratified by occupation, a majority of Ebola infections within each occupation except midwifery and nursing occurred among males. In this evaluation, $67 \%$ of Ebola infections among nondoctor HCWs occurred among males.

In response to Ebola infections among HCWs, the Guinea $\mathrm{MOH}$ is continuing to focus on HCW training and availability of personal protective equipment (PPE). Additionally, the Guinea $\mathrm{MOH}$ is focusing additional resources on investigating cases of Ebola among HCWs as sentinel public health events. Guinea's Ebola case investigation form lacks detailed questions needed to determine routes of transmission among HCWs. An HCW-focused survey tool with questions about specific job tasks, infection control training, use of PPE, and known Ebola exposures in the community, among patients or among fellow HCWs, was implemented in December 2014 and continues to be used to investigate $\mathrm{HCW}$ infections in Guinea. Subsequent analysis of these data might help inform the response to HCW infections by identifying infection prevention and control failures, training gaps, or specific $\mathrm{HCW}$ groups at higher risk for infection. Additionally, analysis of these data might help determine if $\mathrm{HCW}$ are being infected in the health care setting or in the community.

The findings in this report are subject to at least two limitations. First, surveillance data on potential Ebola exposures were not consistently available. For example, data on funeral attendance or contact with a person known to have Ebola were missing for more than half of HCWs with Ebola and almost 
Morbidity and Mortality Weekly Report

TABLE. Number and percentage of health care workers and non-health care workers with confirmed or probable Ebola virus disease (Ebola), by selected characteristics - Guinea, January 1-December 31, 2014

\begin{tabular}{|c|c|c|c|c|c|c|}
\hline \multirow[b]{2}{*}{ Characteristic } & \multicolumn{3}{|c|}{ Health care workers $(n=162)$} & \multicolumn{2}{|c|}{$\begin{array}{l}\text { Non-health care workers } \\
(n=2,048)\end{array}$} & \multirow[b]{2}{*}{$\mathrm{p}$-value } \\
\hline & No. & (\%) & Cases per 1,000 & No. & (\%) & \\
\hline \multicolumn{7}{|l|}{ Sex } \\
\hline Male & 122 & $(75.3)$ & & 952 & $(46.9)$ & $<0.01$ \\
\hline Female & 40 & $(24.7)$ & & 1,080 & $(42.5)$ & \\
\hline Unknown & 0 & $(0)$ & & 16 & $(0.8)$ & \\
\hline \multicolumn{7}{|l|}{ Age group (yrs) } \\
\hline $15-49$ & 139 & $(85.8)$ & & 1,537 & $(75.0)$ & $<0.01$ \\
\hline$\geq 50$ & 23 & $(14.2)$ & & 511 & $(25.0)$ & \\
\hline \multicolumn{7}{|l|}{ Risk factor } \\
\hline Funeral attendance* & 6 & $(10.0)$ & & 174 & $(40.2)$ & $<0.01$ \\
\hline Contact with a person known to have Ebola ${ }^{\dagger}$ & 48 & $(66.7)$ & & 425 & (77.8) & $<0.01$ \\
\hline Isolated at Ebola treatment unit & 126 & (77.8) & & 1,270 & $(62.0)$ & $<0.01$ \\
\hline Mean time to isolation (days) & 4.9 & & & 5.2 & & \\
\hline \multicolumn{7}{|l|}{ Final outcome } \\
\hline Died & 92 & $(56.8)$ & & 1,329 & (64.9) & 0.04 \\
\hline Dead at time of report & 21 & $(13.0)$ & & 626 & (30.9) & $<0.01$ \\
\hline \multicolumn{7}{|l|}{ Occupation ${ }^{\S}$} \\
\hline Doctor & 43 & $(27.0)$ & 26.6 & - & - & \\
\hline Nurse & 40 & $(25.0)$ & 5.5 & - & - & \\
\hline Health technician & 22 & $(14.0)$ & & - & - & \\
\hline Laboratory technician & 8 & $(5.0)$ & 34.7 & - & - & \\
\hline Cleaner & 8 & (5.0) & & - & - & \\
\hline Medical student & 6 & $(4.0)$ & & - & - & \\
\hline Midwife & 6 & (4.0) & 8.7 & - & - & \\
\hline Ambulance driver & 5 & $(3.0)$ & & - & - & \\
\hline Other & 11 & $(14.0)$ & & - & - & \\
\hline Unknown & 8 & $(5.0)$ & & - & - & \\
\hline
\end{tabular}

* Data on funeral attendance were missing for $102(63 \%)$ health care workers and 1,615 (79\%) non-health care workers.

† Data on contact with a person known to have Ebola were missing for $90(56 \%)$ health care workers and 1,502 (73\%) non-health care workers.

$\S$ Only occupations with five or more Ebola cases reported are shown.

three quarters of non-HCWs with Ebola. More complete data collection could increase understanding of potential Ebola exposures. Second, no standard definition of an HCW exists. For Ebola surveillance purposes, a broader definition of HCW was used than was used in the $\mathrm{MOH}$ estimate of the number of $\mathrm{HCW}$, which likely resulted in an overestimate of the actual incidence of Ebola infection among HCWs.

Ebola infections among HCWs are an important focus area for the outbreak response, and an increased understanding of potential Ebola exposures is needed to better tailor infection prevention and control trainings and practices. The finding that HCWs were less likely than non-HCWs to report contact with a person known to have Ebola suggests a failure to identify Ebola cases in patients who present to non-ETU settings. The finding that only one infected HCW worked at an ETU underscores the importance of infection prevention and control. HCWs working in ETUs might have had more comprehensive infection prevention and control training, more access to infection prevention and control resources such as PPE, more practice donning and doffing PPE, and heightened awareness of Ebola compared with HCWs in
non-ETU settings. Currently, substantial uncertainty exists about Ebola infections among HCWs, including source and place of exposure, reasons for delay in isolation after symptom onset, and particular job tasks that might increase the risk for infection. An enhanced understanding of HCW risks factors for infection, along with continuous infection prevention and control efforts, are necessary to prevent Ebola infection in this high-risk occupational group.

\section{Acknowledgments}

Ministry of Health, Guinea; World Health Organization; Médecins Sans Frontières; Guinea Ebola Response Team, CDC.

\footnotetext{
${ }^{1}$ Divsion of Population Health, National Center for Chronic Disease Prevention and Health Promotion, CDC; ${ }^{2}$ Division of Global HIV/AIDS, Center for Global Health, CDC; ${ }^{3}$ Division of STD Prevention, National Center for HIV/ AIDS, Viral Hepatitis, STD, and TB Prevention, CDC; ${ }^{4}$ Division of Global Health Protection, Center for Global Health, CDC; ${ }^{5}$ Guinea Ministry of Health and Public Hygiene; ${ }^{6}$ Division of Surveillance, Hazard Evaluations, and Field Studies, National Center for Occupational Safety and Health, CDC; ${ }^{7}$ Division of Parasitic Diseases and Malaria, Center for Global Health, CDC; ${ }^{8}$ World Health Organization, Conakry, Guinea.

Corresponding author: Margaret Grinnell, mhgrinnell@gmail.com.
} 


\section{References}

1. Briand S, Bertherat E, Cox P, et al. The international Ebola emergency. N Engl J Med 2014;371:1180-3.

2. World Health Organization. Fact sheet no. 103: Ebola virus disease. Available at http://www.who.int/mediacentre/factsheets/fs103/en.

3. Kilmarx PH, Clarke KR, Dietz PM, et al. Ebola virus disease in health care workers-Sierra Leone, 2014. MMWR Morb Mortal Wkly Rep 2014;63:1168-71.

4. Dixon MG, Schafer IJ. Ebola viral disease outbreak-West Africa, 2014. MMWR Morb Mortal Wkly Rep 2014;63:548-51.
5. Guinea Ministry of Planning. Publication of preliminary results of the Third General Census of Population and Housing conducted March 1-April 2, 2014 [French]. Conakry, Guinea: Guinea Ministry of Planning; 2014. Available at http://www.stat-guinee.org/index.php/ result-prelim-rgph3?download=55: res-pre-rgph3.

6. Guinea Division of Human Resources. Census of health workers 2009 [French]. Conakry, Guinea: Guinea Division of Human Resources; 2011.

7. US Central Intelligence Agency. The world factbook: Guinea. Available at https://www.cia.gov/library/publications/the-world-factbook/geos/gv.html.

8. Matanock A, Arwady MA, Ayscue P, et al. Ebola virus disease cases among health care workers not working in Ebola treatment units-Liberia, June-August, 2014. MMWR Morb Mortal Wkly Rep 2014;63:1077-81. 


\title{
Measles Outbreak Associated with Vaccine Failure in Adults - Federated States of Micronesia, February-August 2014
}

\begin{abstract}
Lucy Breakwell, $\mathrm{PhD}^{1}$; Edna Moturi, $\mathrm{MD}^{2}$; Louisa Helgenberger, $\mathrm{MPH}^{5}$; Sameer V. Gopalani, $\mathrm{MPH}^{5}$; Craig Hales, MD 3 ; Eugene Lam, $\mathrm{MD}^{2}$; Umid Sharapov, $\mathrm{MD}^{2}$; Maribeth Larzelere, $\mathrm{MPH}^{3}$; Eliaser Johnson, $\mathrm{MD}^{6}$; Carolee Masao, $\mathrm{MD}^{7}$; Eleanor Setik ${ }^{8}$; Lisa Barrow, $\mathrm{MSc}^{5}$; Samantha Dolan, $\mathrm{MPH}^{2}$; Tai-Ho Chen, $\mathrm{MD}^{4}$; Minal Patel, $\mathrm{MD}^{2}$; Paul Rota, $\mathrm{PhD}^{3}$; Carole Hickman, $\mathrm{PhD}^{3}$; William Bellini, $\mathrm{PhD}^{3}$; Jane Seward, $\mathrm{MD}^{3}$; Greg Wallace, $\mathrm{MD}^{3}$; Mark Papania, $\mathrm{MD}^{3}$
\end{abstract}

On May 15, 2014, CDC was notified of two laboratoryconfirmed measles cases in the Federated States of Micronesia (FSM), after 20 years with no reported measles. FSM was assisted by the World Health Organization (WHO), the United Nations Children's Fund (UNICEF), and CDC in investigating suspected cases, identify contacts, conduct analyses to guide outbreak vaccination response, and review vaccine cold chain practices. During February-August, three of FSM's four states reported measles cases: Kosrae (139 cases), Pohnpei (251), and Chuuk (3). Two thirds of cases occurred among adults aged $\geq 20$ years; of these, $49 \%$ had received $\geq 2$ doses of measles-containing vaccine (MCV). Apart from infants aged $<12$ months who were too young for routine vaccination, measles incidence was lower among children than adults. A review of current cold chain practices in Kosrae revealed minor weaknesses; however, an absence of historical cold chain maintenance records precluded an evaluation of earlier problems. Each state implemented vaccination campaigns targeting children as young as age 6 months through adults up to age 57 years. The preponderance of cases in this outbreak associated with vaccine failure in adults highlights the need for both thorough case investigation and epidemiologic analysis to guide outbreak response vaccination. Routine childhood vaccination coverage achieved in recent years limited the transmission of measles among children. Even in areas where transmission has not occurred for years, maintaining high 2-dose MCV coverage through routine and supplemental immunization is needed to prevent outbreaks resulting from increased measles susceptibility in the population.

As an independent country linked to the United States through a Compact of Free Association, FSM receives immunization funding and technical support from the U.S. domestic vaccination program. FSM comprises 607 islands dispersed across 1 million square miles (2.6 million square kilometers) of the western Pacific Ocean. According to the preliminary 2010 census, the population of 102,624 resides in four states: Chuuk (48,651 residents), Pohnpei $(35,981)$, Yap $(11,376)$, and Kosrae $(6,616)(1)$.

As a member country of the WHO Western Pacific Region, FSM is committed to eliminating measles through achieving and maintaining $\geq 95 \%$ vaccination coverage with 2 doses of
MCV for each birth cohort of children (2). A single dose of monovalent measles vaccine was introduced in FSM in 1963 and was replaced in 1982 with the measles-mumps-rubella (MMR) vaccine, administered to infants at age 9 months (3). Since the late 1980s, FSM has maintained single-dose MMR vaccination coverage of $>70 \%$, most recently exceeding $90 \%$ (3). In 1995, a second dose of MMR was introduced. Second dose coverage increased from $50 \%$ in 2000 to $85 \%$ in 2007 , and presently remains around $75 \%$ (3). Currently, the first MMR dose is administered at age 12 months, followed by a second dose at age 13 months. Supplementary immunization activities (SIAs), campaigns targeting particular age groups to rapidly increase population immunity, were conducted in Pohnpei in 2011 and in Chuuk in 2004, 2010, and 2013. In Chuuk, SIAs targeted children aged 1-14 years and attained approximately $90 \%$ coverage (3). Despite coverage levels $<95 \%$, no measles cases had been reported by FSM since an outbreak during 1991-1994, which was associated with 887 cases and 13 deaths (4).

\section{Outbreak}

Beginning on February 16, 2014, several patients were evaluated at Kosrae State Hospital for acute onset of fever and rash. No history of travel or specific disease exposures was available in the hospital records. Initial clinical diagnoses were dengue fever or chikungunya. However, during the next several months, as more persons with fever and rash were examined at the hospital, measles was considered as a possible diagnosis. On May 15, FSM reported that serum samples collected from two persons with fever and rash had tested positive for measles-specific immunoglobulin M (IgM) antibodies. During the subsequent investigation, WHO measles case definitions were used (5). A suspected measles case was defined as an illness consisting of fever and a maculopapular rash and cough, coryza, or conjunctivitis in a person of any age, or any illness in a person in whom a clinician suspected measles. Cases were laboratory-confirmed by detection of measles virus nucleic acid from a throat or nasal swab, or measles-specific IgM in a serum sample. Suspected cases were epidemiologically confirmed if they had a rash onset date within 7-21 days of another laboratory-confirmed or epidemiologically confirmed case in 
the same municipality. Suspected cases with no specimens or with indeterminate laboratory results that could not be epidemiologically linked were considered clinically compatible cases (2). Vaccination history was verified through vaccination records and historical SIA participant lists.

During February 16-June 10, a total of 139 measles cases were detected in Kosrae through febrile rash illness surveillance at the hospital, contact tracing, and a retrospective investigation of earlier fever and rash cases (Figure 1). The first measles cases in Pohnpei were detected on May 12, and during May 12-August 31, 251 cases were reported. The first case in Chuuk was detected on July 24; three cases were reported there during July 24-August 26 (rash onset date could not be confirmed for one patient) (Figure 1). This resulted in a total of 393 measles cases from the three states. No confirmed cases were reported from Yap; 16 suspected cases were investigated and ruled out following negative laboratory results.

Among all 393 cases, 140 (36\%) were laboratory confirmed, $244(62 \%)$ were epidemiologically confirmed, and nine (2\%) were clinically compatible. Cases were reported for all municipalities in Kosrae and on the main island of Pohnpei, along with one municipality (out of 40) in Chuuk. The median patient age was 24 years (range $=3$ weeks-61 years), with 250 $(64 \%)$ patients aged $>19$ years. Overall attack rates were highest among infants aged $<12$ months ( 56 cases; 22 cases per 1,000 population) followed by adults aged 20-29 years (119; seven per 1,000), and 30-39 years (76; six per 1,000).
Among the 393 measles patients, 306 had vaccination records and the remaining 87 were classified as having unknown vaccination status including 74 adults. Among those with vaccination records, $216(71 \%)$ had received at least one MCV dose before the outbreak, including 169 (96\%) of adults aged $>19$ years. Among adult patients with vaccination records, $123(70 \%)$ had received $\geq 2$ doses of MCV. Among the 90 unvaccinated patients, $54(60 \%)$ were aged $<12$ months and therefore ineligible for routine vaccination. Among 89 children and adolescents aged $1-19$ years with measles, 29 (33\%) were unvaccinated; seven (3\%) adults were unvaccinated (Figure 2).

Approximately one third of measles patients $(n=124)$ required hospitalization, and one death was reported (a boy aged 21 months from Pohnpei). Genetic analysis of the nucleotide sequences of measles viruses circulating in Kosrae, Pohnpei, and Chuuk was performed at CDC and identified genotype B3, similar to the B3 lineage reported from a 2013-2014 outbreak in the Philippines and many other countries (G).

\section{Outbreak Response}

Vaccination. Each of FSM's four states conducted a mass vaccination campaign to rapidly increase population immunity. In Kosrae, the campaign was conducted during May 22-June 15 and targeted persons aged 6 months- 57 years. This campaign included vaccination record checks, and only persons who did not have two documented doses of MCV were vaccinated (4,360 doses administered). The campaigns

FIGURE 1. Number of measles cases by rash onset date* - Kosrae, Phonphei, and Chuuk states, Federated States of Micronesia, $2014^{\dagger \S}$

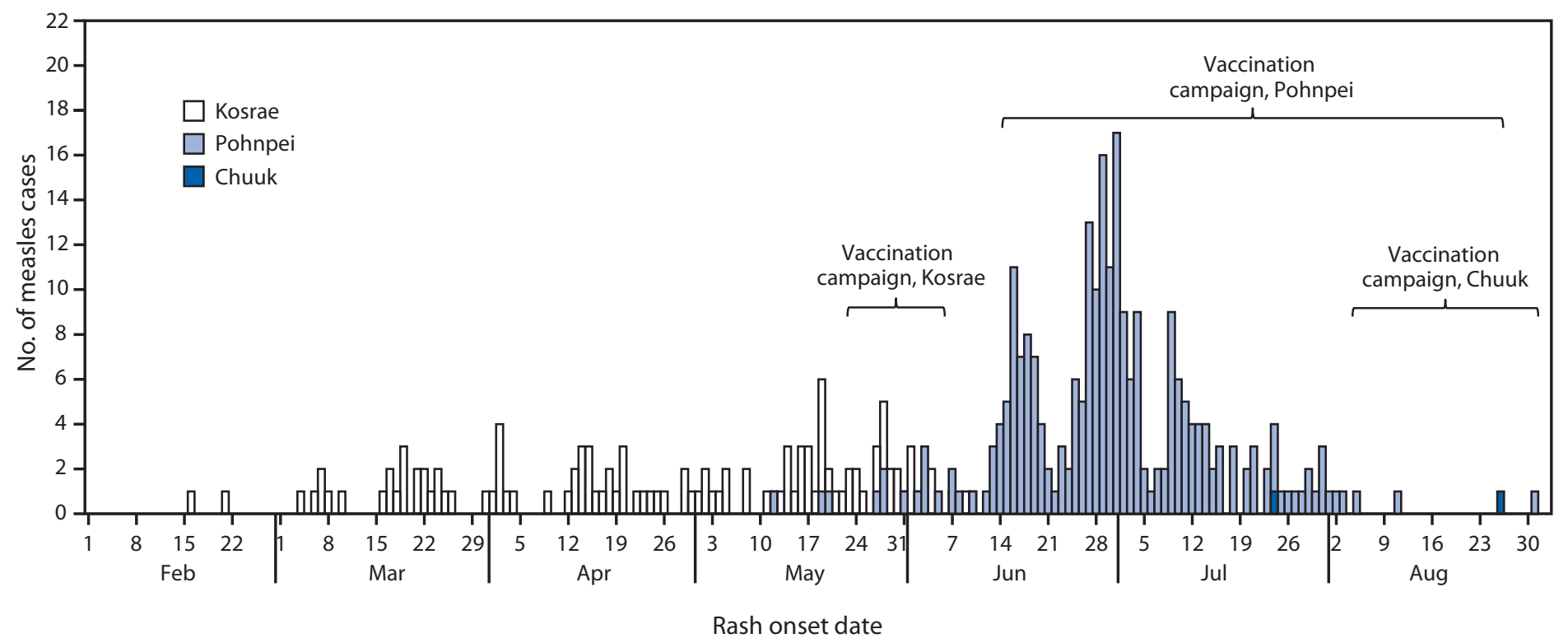

\footnotetext{
* Rash onset date was missing for 21 cases in Kosrae, two in Pohnpei, and one in Chuuk.

† Vaccination campaign on Pohnpei proper and the lagoon islands occurred during June 16-August 25 and on the outer islands on August 12 and during September 18-20.

$\S$ Chuuk vaccination campaign on the lagoon islands occurred during August 4-October 22 and on the outer islands during September $26-$ December 17.
} 
FIGURE 2. Number of reported measles cases $(\mathrm{N}=393)$, by age group of patients and number of measles-containing vaccine doses Kosrae, Pohnpei, and Chuuk states, Federated States of Micronesia, February-August 2014

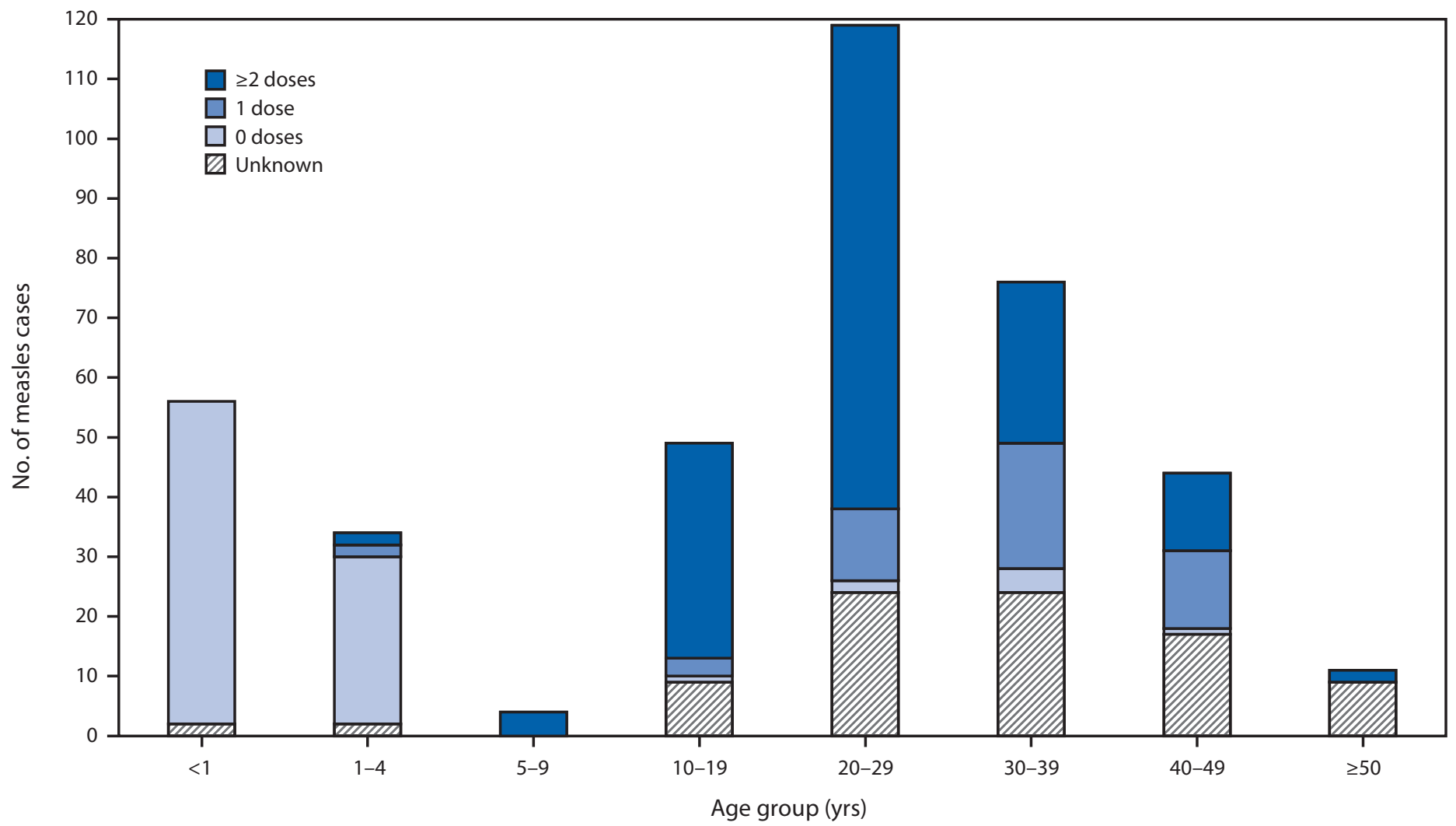

conducted in Pohnpei and Chuuk targeted all persons aged 6 months -49 years, without checking vaccination records. The campaigns occurred during June 16-September 20 in Pohnpei (29,159 doses administered) and during August 4-December 17 in Chuuk (35,871 doses administered). The campaign in Yap was conducted during June 2-October 12, and 1,998 doses were administered. Persons aged 1-18 years were vaccinated only if they did not have two documented MMR doses, and persons aged 19-49 years were vaccinated without checking vaccination status. On the basis of vaccine doses administered and population census estimates, the percentages of the target populations reached by the campaigns were estimated to be 90\% in Kosrae, 95\% in Pohnpei, 85\% in Chuuk, 42\% in Yap, and $87 \%$ in FSM overall. The level of immunity achieved through the campaigns appeared to be sufficient to interrupt transmission and stop the outbreak. No cases were reported in FSM after August 31, 2014.

Review of cold chain practices in Kosrae. A limited assessment of vaccine storage equipment and handling practices was conducted at Kosrae Public Health Clinic, the site responsible for vaccine storage and distribution in Kosrae. The clinic provides vaccines to children through statewide campaigns, walk-in visits, and scheduled well-baby appointments, as well as outreach sessions at schools. Some inadequacies in vaccine management were identified, including the use of expired or nonrecommended temperature monitoring equipment, freezing temperatures occurring during vaccine transport, the lack of access to a back-up generator, and the absence of documentation of historical temperature monitoring; the latter precluded the assessment of any past cold chain failures that might have affected the potency of MMR.

\section{Discussion}

After 20 years with no reported cases of measles, FSM reported 393 measles cases during February-August, 2014. Delays in detecting the initial measles cases allowed the outbreak to spread and serve as a reminder that measles should be suspected in any case of febrile rash illness, even if the disease has not been seen in the area for years. Approximately two thirds of cases occurred among adults, most of whom had received $\geq 1$ dose of $\mathrm{MCV}$, with many receiving 2 doses. Although measles is typically a childhood disease, outbreaks affecting all age groups have occurred, particularly in populations too small to sustain endemic transmission $(4,7,8)$. However, in this outbreak, the extent of transmission among adults with documented receipt of MMR vaccine, including 
many with 2 doses, is atypical. Administration of appropriately stored and handled measles vaccine usually produces long-lasting immunity when administered to children aged $12-15$ months. Approximately $2 \%-5 \%$ of children who receive 1 dose of MCV fail to develop an appropriate immune response (primary vaccine failure) (9). Most children with primary vaccine failure respond appropriately to a subsequent dose. Secondary vaccine failure refers to waning of vaccine-induced immunity to nonprotective levels. Although distinguishing between primary and secondary vaccine failure is difficult, detection of measles antibody with high avidity in a person with measles suggests secondary failure. Antibody avidity testing is currently being conducted at CDC on specimens collected from cases during this outbreak.

Vaccine failure can result from improper vaccine storage and handling, leading to decreased vaccine potency (10). FSM is a tropical country with multiple vaccine storage challenges, including high ambient temperatures, frequent power outages, and inter-island shipping issues. Although some problems with the vaccine cold chain were identified in Kosrae, it was not possible to assess whether these had affected the potency of vaccines currently in stock because the outbreak response rapidly exhausted existing vaccine supplies. However, few measles cases in children aged $<9$ years were identified, and most of these occurred in unvaccinated children, which suggests recent cold chain practices were adequate. Historical cold chain lapses are the most plausible explanation for prevalent vaccine failure seen in adults in this outbreak. Earlier problems with vaccine storage and handling might have resulted in suboptimal protection of persons vaccinated decades earlier. Correction of these problems would be expected to lead to protection among persons recently vaccinated. A vaccine effectiveness study was conducted in Pohnpei; when available, the study's findings might determine whether vaccine effectiveness changed over time.

Although most measles outbreaks are caused by a failure to vaccinate all persons who need vaccine, vaccine failure among adults played a major role in this outbreak $(4,7,8)$. Routine vaccination programs and SIAs provided high population immunity among children, with limited transmission in this age group. A series of rapid outbreak response vaccination campaigns increased population immunity and ended the outbreak. The potential role of cold chain lapses in adult vaccine failure highlights the challenges associated with cold chain management in resource-limited settings. These types of challenges might be reduced through availability of more thermostable vaccines. Continued efforts to reach and maintain $\geq 95 \%$ 2-dose MCV vaccination coverage are needed to achieve sustained measles elimination in FSM.

\section{Summary \\ What is already known on this topic?}

Measles outbreaks occur when the virus is introduced into a population with inadequate immunity, and are almost always caused by failure to vaccinate a high proportion of susceptible persons. Although measles is typically a disease of childhood, persons of all ages can acquire measles, especially in small, isolated, island populations like the Federated States of Micronesia (FSM), where measles has not circulated for many years.

What is added by this report?

After 20 years with no reported measles cases, FSM experienced a moderately large outbreak in 2014 with 393 cases reported. Vaccinated adults accounted for more than half of all cases, demonstrating that in rare circumstances vaccine failure can play a role in measles susceptibility. The cause of the vaccine failure in adults was not determined, although historical cold chain lapses might have reduced vaccine potency and resulted in accumulation of susceptible persons. Moderately high routine 2-dose coverage among children limited transmission in this age group, with the exception of infants who were too young to be vaccinated.

What are the implications for public health practice?

Sustained high 2-dose measles vaccination coverage through routine immunization programs and supplemental immunization activities is needed to prevent the spread of measles outbreaks, even where vaccine failure is a key component of the outbreak. Rapid mass vaccination campaigns can be effective in limiting outbreak spread and should be tailored to the pattern of susceptibility revealed by the outbreak.

\section{Acknowledgments}

FSM Department of Health and Social Affairs; clinical, laboratory, and administrative staff members from the Departments of Health Services of Kosrae, Pohnpei, Chuuk, and Yap states; FSM National and State Immunization Program and staff members.

\footnotetext{
${ }^{1}$ Division of Bacterial Diseases, National Center for Immunization and Respiratory Diseases, CDC; ${ }^{2}$ Global Immunization Division, Center for Global Health, CDC; ${ }^{3}$ Division of Viral Diseases, National Center for Immunization and Respiratory Diseases, CDC; ${ }^{4}$ Division of Global Migration and Quarantine, National Center for Emerging and Zoonotic Infectious, CDC; ${ }^{5}$ Department of Health and Social Affairs, Government of the Federated States of Micronesia; ${ }^{6}$ Division of Primary Health Care, Pohnpei State, Federated States of Micronesia; ${ }^{7}$ Department of Health Services, Kosrae State, Federated States of Micronesia; ${ }^{8}$ Department of Health Services, Chuuk State, Federated States of Micronesia.

Corresponding author: Mark Papania,mpapania@cdc.gov, 404-639-8716.

\section{References}

1. Federated States of Micronesia Office of Statistics, Budget and Economic Management, Overseas Development Assistance, and Compact Management. FSM 2010 census preliminary results. Federated States of Micronesia; 2015. Available at http://www.sboc.fm/index.
} 
2. World Health Organization Regional Office for the Western Pacific. Field guidelines for measles elimination. Geneva, Switzerland: World Health Organization; 2004. Available at http://www.wpro.who.int/ publications/docs/FieldGuidelines_for_MeaslesElimination_0F24.pdf.

3. Güriș D, Auerbach SB, Vitek C, et al. Measles outbreaks in Micronesia, 1991 to 1994 . Pediatr Infect Dis J 1998;17:33-9.

4. World Health Organization Regional Office for the Western Pacific. Federated States of Micronesia: country profile-measles elimination. Geneva, Switzerland: World Health Organization; 2015. Available at http://www.wpro.who.int/immunization/documents/measles_country_ profile_sep2014_fsm.pdf.

5. World Health Organization. Immunizations, vaccines, and biologicals: WHO-recommended surveillance standard of measles. Geneva, Switzerland: World Health Organization; 2015. Available at http://www. who.int/immunization/monitoring_surveillance/burden/vpd/ surveillance_type/active/measles_standards/en.
6. World Health Organization. Progress towards measles elimination, Philippines, 1998-2014. Wkly Epidemiol Rec 2015;90:149-59.

7. Hyde TB, Dayan GH, Langidrik JR, et al. Measles outbreak in the Republic of the Marshall Islands, 2003. Int J Epidemiol 2006;35:299-306.

8. CDC. Measles outbreak and response-Fiji, February-May 2006. MMWR Morb Mortal Wkly Rep 2006;55:963-6.

9. CDC. Epidemiology and prevention of vaccine-preventable diseases: measles [Chapter 13]. In: The Pink Book. 13th ed. Atlanta, GA: CDC; 2015. Available at http://www.cdc.gov/vaccines/pubs/pinkbook/meas.html.

10. Fowotade A, Okonko IO, Nwabuisi C, Bakare RA, Fadeyi A, Adu FD. Measles vaccine potency and sero-conversion rates among infants receiving measles immunization in Ilorin, Kwara State, Nigeria. J Immunoassay Immunochem 2015;36:195-209. 


\section{Percentage* of Mental Illness-Related ${ }^{\dagger}$ Physician Office Visits by Persons Aged $\geq 18$ Years, by Physician Specialty $§$ and Region ${ }^{\Uparrow}$ — United States, 2012}

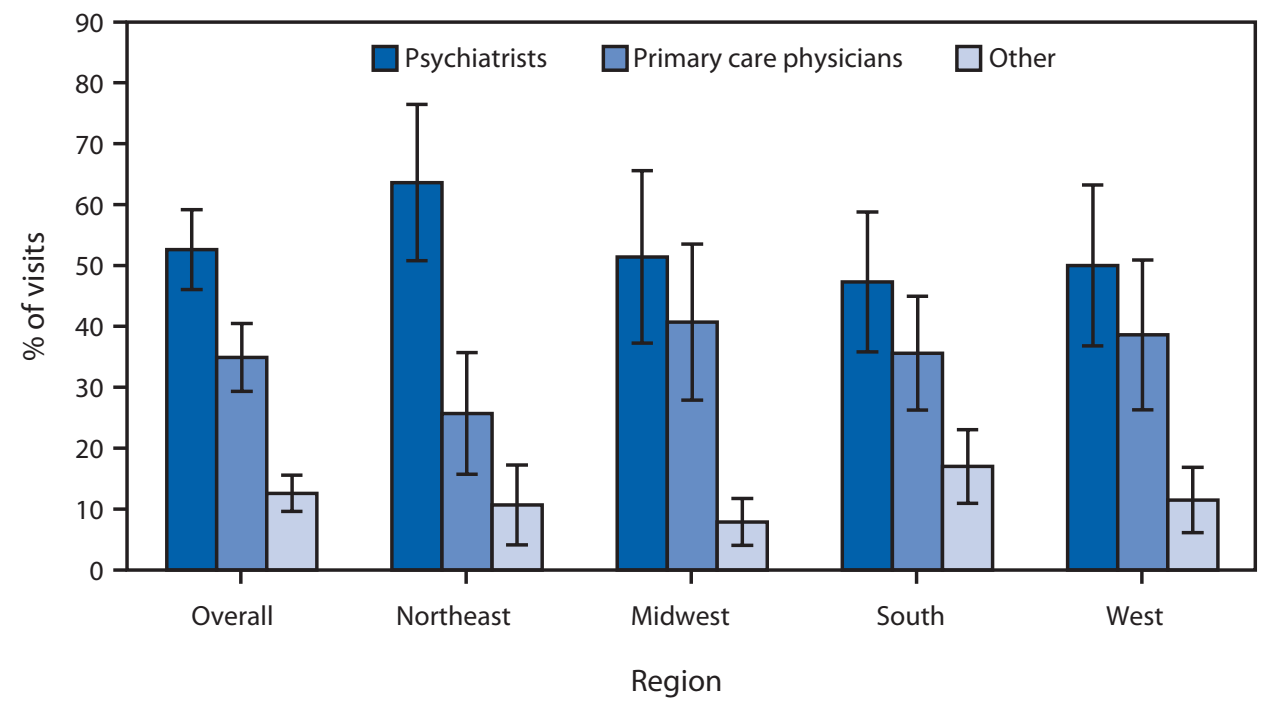

* With $95 \%$ confidence intervals.

† A mental health visit was defined by the presence of at least one of the following primary listed reasons for visit classifications: symptoms referable to psychological and mental disorders (1100-1199) and mental disorders (2300-2349). A reason for visit is defined by a patient's complaint(s), symptom(s), or other reason(s) for the visit, and up to three can be indicated for each visit.

$\S$ Other includes visits to all other combined physician specialties.

I Estimate for visits to other physicians in the Northeast does not meet standards of reliability and precision because relative standard error $>0.30$.

In 2012, about one half (52.6\%) of mental health-related doctor visits made by adults were to psychiatrists, $34.9 \%$ to primary care physicians, and $12.6 \%$ to other physicians. In the Northeast, mental health-related visits were more frequently made to psychiatrists (63.6\%) compared with primary care physicians (25.7\%), whereas in other regions of the country the differences were not significant. The percentage of visits to other physicians was significantly lower compared with psychiatrists and compared with primary care physicians in all regions.

Source: National Ambulatory Medical Care Survey data, available at http://www.cdc.gov/nchs/ahcd/ahcd_questionnaires.htm. Reported by: Donald Cherry, MS, 301-458-4782, dcherry@cdc.gov; Linda McCaig, MPH; Michael Albert, MD. 


The Morbidity and Mortality Weekly Report (MMWR) Series is prepared by the Centers for Disease Control and Prevention (CDC) and is available free of charge in electronic format. To receive an electronic copy each week, visit MMWR's free subscription page at http://www.cdc.gov/mmwr/mmwrsubscribe.html. Paper copy subscriptions are available through the Superintendent of Documents, U.S. Government Printing Office, Washington, DC 20402; telephone 202-512-1800.

Readers who have difficulty accessing this PDF file may access the HTML file at http://www.cdc.gov/mmwr/index2015.html. Address all inquiries about the MMWR Series, including material to be considered for publication, to Executive Editor, MMWR Series, Mailstop E-90, CDC, 1600 Clifton Rd., N.E., Atlanta, GA 30329-4027 or to mmwrq@cdc.gov.

All material in the MMWR Series is in the public domain and may be used and reprinted without permission; citation as to source, however, is appreciated. Use of trade names and commercial sources is for identification only and does not imply endorsement by the U.S. Department of Health and Human Services.

References to non-CDC sites on the Internet are provided as a service to $M M W R$ readers and do not constitute or imply endorsement of these organizations or their programs by CDC or the U.S. Department of Health and Human Services. CDC is not responsible for the content of these sites. URL addresses listed in $M M W R$ were current as of the date of publication.

ISSN: 0149-2195 (Print) 